\title{
Adsorption of dyes using different types of clay: a review
}

\author{
Aderonke Ajibola Adeyemor ${ }^{1}$ Idowu Olatunbosun Adeoye ${ }^{2} \cdot$ Olugbenga Solomon Bello $^{2}$
}

Received: 15 September 2014 / Accepted: 11 August 2015/Published online: 2 September 2015

(c) The Author(s) 2015. This article is published with open access at Springerlink.com

\begin{abstract}
Increasing amount of dyes in the ecosystem particularly in wastewater has propelled the search for more efficient low-cost adsorbents. The effective use of the sorption properties (high surface area and surface chemistry, lack of toxicity and potential for ion exchange) of different clays as adsorbents for the removal of different type of dyes (basic, acidic, reactive) from water and wastewater as potential alternatives to activated carbons has recently received widespread attention because of the environmental-friendly nature of clay materials. Insights into the efficiencies of raw and modified/activated clay adsorbents and ways of improving their efficiencies to obtain better results are discussed. Acid-modified clay resulted in higher rate of dye adsorption and an increased surface area and porosity (49.05 $\mathrm{mm}^{2}$ and $53.4 \%$ ). Base-modified clay has lower adsorption capacities, while $\mathrm{ZnCl}_{2}$-modified clay had the least rate of adsorption with a surface area of $44.3 \mathrm{~mm}^{2}$ and porosity of $43.4 \%$. This review also explores the grey areas of the adsorption properties of the raw clays and the improved performance of activated/modified clay materials with particular reference to the effects of $\mathrm{pH}$, temperature, initial dye concentration and adsorbent dosage on the adsorption capacities of the clays. Various challenges encountered in using clay materials are highlighted and a number of future prospects for the adsorbents are proposed.
\end{abstract}

Olugbenga Solomon Bello

osbello06@gmail.com

1 Department of Inorganic and Physical Chemistry, Indian Institute of Science, Bangalore 560012, India

2 Department of Pure and Applied Chemistry, Ladoke Akintola University of Technology, P. M. B. 4000, Ogbomoso, Oyo State, Nigeria
Keywords Wastewater - Dyes · Clay · Adsorption · Low-cost adsorbents

\section{Introduction}

Water pollution represents a great challenge and activated carbon is a common adsorbent used to remove hazardous contaminants from wastewater (Zakaria et al. 2009). Dyes are coloured compounds suitable for colouring textiles, wool, leather, paper and fibres. Natural dyes such as indigo have been in use for over 5000 years. Synthetic dyes have replaced natural dyes because of their low cost and vast range of new colours (Gabriel and Hong 2008). Today, there are more than 10,000 dyes with different chemical structures available commercially (Arivoli and Thenkuzhali 2008). Effluents of textile, paper and pulp, paint, printing and cosmetic industries contain significant amount of these dyes and must be treated to bring down their concentration to permissible limit before discharging into water bodies as required by environmental regulation act (Aksu 2005). The high solubility of dyes in water results in their wide dissemination into the environment, thus making them detrimental to crops, aquatic life and human health (Zhao et al. 2011). The increasing occurrence of many synthetic and natural organic substances in natural water led to the importance of using adsorption technique as one of the most effective methods of removing impurities from wastewater, because several dyes and their degradation (by-) products are toxic to living organisms (Abd El-Latif et al. 2010; Kannan and Sundaram 2001). Therefore, removal of dyes is an important aspect of wastewater treatment before discharge, as it is difficult to remove dyes from effluent because they are not easily degradable and are generally not removed from wastewater by the 
conventional wastewater purification systems (Abd ElLatif et al. 2010; Kargi and Ozmihci 2004; Chen et al. 2001).

Adsorption is a major industrial separation technique for the purification of effluent media. It is a mass transfer operation through which a solid material can selectively remove dissolved components from an aqueous solution by attracting the dissolved solute to its surface. Therefore, it involves the interphase accumulation of concentrated substances at a surface or at the interphase. This separation technique finds wide application in the removal of dye from aqueous media. Specifically, adsorption finds application in textile, leather, dyeing, cosmetics, plastics, food and paper industries where water recovery is very essential. To achieve and sustain efficient recovery of the desired water quality, a careful selection of adsorbent is of paramount importance (Abd El-Latif et al. 2010; Albarins and Hela 1993; Menkiti and Onukwuli 2011). However, the array of adsorbents available in our local markets is imported from other countries, in spite of the abundance of raw materials in Nigeria for the production of the required quantity of adsorbents for local industries (Menkiti and Onukwuli 2011). In literature, a number of adsorbents have been investigated for the removal of dyes from wastewater. Some examples amongst others include: apple pomace and wheat straw (Robinson et al. 2002); corncob and barley husk (Robinson et al. 2001); maize cob, wood and rice hull (Low and Lee 1997); banana stalk (Bello et al. 2012a); groundnut hull (Bello et al. 2012b; Din et al. 2009); oil palm ash (Foo and Hameed 2009a; Hasan 2008); oil palm fruit fibre (Bello 2013); cocoa pod husks (Bello and Ahmad 2011a); spent tea leaves (Hameed 2009a); ginger waste (Ahmad and Kumar 2010); degreased coffee bean (Baek et al. 2010); mango peels (Bello and Ahmad 2011b); rice husk (Foo and Hameed 2009b; Yahaya et al. 2010a, b, 2011a, b); periwinkle shell (Bello et al. 2008; Bello and Ahmad 2011c, d); palm kernel shell (Zawani et al. 2009); coconut shell (Bello and Ahmad 2012b); Imperata cylindrica leaf (Bello and Semire 2012); rubber seed coat (Bello and Ahmad 2012a); ackee apple (Blighia sapida) seeds (Bello et al. 2013a); de-oiled soya (Mittal et al. 2005); cassava peel (Rajeshwarisivaraj et al. 2001); bean pods (Cabal et al. 2009); Luffa cylindrica fibres (Demir et al. 2008); papaya seeds (Hameed 2009b); and fly ash (Bello et al. 2013b). Very recently, the use of metal organic frameworks (MOFs) in dye adsorption has been explored (Adeyemo et al. 2012; Han et al. 2015; Yan et al. 2014; Chen et al. 2012a; Yue et al. 2014).

Activated carbon and clay are among many different adsorbents used in the adsorption technique (Zakaria et al. 2009). Activated carbon has been successfully used in removing coloured organic species and is the most widely used adsorbent due to its high capacity of adsorption of organic materials (Joan et al. 1997; Markovska et al. 2001; Chen et al. 2001) and its effectiveness and versatility (Chen et al. 2011; Purkait et al. 2007). However, due to it being a limited natural resource, slow adsorption kinetics and low adsorption capacity of bulky adsorbate because of its microporous nature, disposal problems and also the high cost and difficulty of regeneration, a search for cheap, effective adsorbents such as clay derivatives has becomes important (Abd El-Latif et al. 2010; Malik 2004; Nakagawa et al. 2004; Tanthapanichakoon et al. 2005; Valix et al. 2004; Joo et al. 2009). Clay minerals have been extensively studied because of their strong sorption and complexation ability (Sheng et al. 2012). In recent years, the use of soil clay materials to replace commercially available adsorbents has attracted much attention due to their low cost, ready availability, high surface area, lack of toxicity and potential for ion exchange (Chen et al. 2011; Gurses et al. 2006; Murray 2000). Their unique properties including high specific surface area and surface chemistry, a variety of surface and structural properties, chemical and mechanical stabilities give these materials a broad range of applications (Chen et al. 2011; Tulin and Gamze 2009; Liu and Zhang 2007). Many clay minerals are widely used due to their organic molecule adsorption-desorption properties (Al-Asheh and Abu-Aitah 2003; Hu et al. 2005; Kumar 2006; Ozcan et al. 2007).

Clay refers to a naturally occurring material composed primarily of fine-grained minerals, which is/might be plastic in nature at appropriate water contents and will harden when dried or fired. Although clay usually contains phyllosilicates, it may contain other materials that may impart plasticity and harden when dried or fired. Associated phases in clay may include materials that do not impart plasticity and organic matter (Guggenheim and Martin 1995). Clay minerals are hydrous aluminosilicates with fine particle size; they are composed of two basic building blocks: silicon-oxygen tetrahedron $\left(\mathrm{Si}_{2} \mathrm{O}_{5}\right)^{2-}$ and aluminium octahedron (gibbsite sheet). Tetrahedral sheets are composed of individual tetrahedrons which share every three out of four oxygens. They are arranged in a hexagonal pattern with the basal oxygens linked and the apical oxygens pointing up/down. Octahedral sheets are composed of individual octahedrons that share edges composed of oxygen and hydroxyl anion groups with $\mathrm{Al}^{3+}, \mathrm{Mg}^{2+}$ and $\mathrm{Fe}^{2+}$ typically serving as the coordinating cation. These octahedrons are arranged in a hexagonal pattern (Guggenheim and Martin 1995; Zakaria et al. 2009).

Clay can remove approximately $70 \%$ of the waste of water in a water removal system and the remaining $30 \%$ can be removed using activated carbon (Guggenheim and Martin 1995; Zakaria et al. 2009). The fate and mobility of adsorbates are greatly affected by their strong interaction with natural clay and oxide minerals that are widely present in the 
natural environment (Sheng et al. 2013; Miller et al. 2010; Miller and Wang 2012; Parekh et al. 2008; Rao et al. 2007). The uptake process is generally affected by several environmental factors such as quantity and type of ions, solution $\mathrm{pH}$, ionic strength, temperature and type of dye (Sheng et al. 2011, 2013; Yang et al. 2011b). Temperature plays a significant role in the dynamic uptake of metal ions, the transformation of surface complexation structures and the stability of various metal precipitates (Yang et al. 2011a).

Naturally occurring raw and modified clays have shown good results as adsorbents for the removal of various metals, organic compounds and dyes (Guggenheim and Martin 1995; Zakaria et al. 2009). Fan and co-workers investigated the effects of $\mathrm{pH}$, ionic strength and temperature on the sorption of $\mathrm{Eu}(\mathrm{III})$ on attapulgite in the presence and absence of fulvic acid (FA) and humic acid (HA). The results indicated that the sorption of $\mathrm{Eu}(\mathrm{III})$ on attapulgite was strongly dependent on $\mathrm{pH}$ and ionic strength and independent of temperature at low $\mathrm{pH}$, despite slight increase with increasing temperature at high $\mathrm{pH}$. The mechanism and species of Eu(III) sorption to attapulgite were changed in the different addition sequences. The presence of natural organic matter and $\mathrm{pH}$ values had significant influence on the species of $\mathrm{Eu}(\mathrm{III})$, which is crucial to the chemical behaviour of Eu(III) in the environment (Fan et al. 2009). The sorption of $\mathrm{Co}(\mathrm{II})$ and $\mathrm{Sr}(\mathrm{II})$ on kaolinite, illite, hectorite and montmorillonite studied by Chen and Hayes under a range of $\mathrm{pH}$ and background electrolyte showed that $\mathrm{Co}$ (II) formed different types of surface complexes on the clay surfaces depending on solution $\mathrm{pH}$ and $\mathrm{Na}$ ion concentration, while the $\mathrm{Na}$ ion concentration dependence of the $\mathrm{Sr}$ (II) sorption experiments suggested weaker bonding between sorbed $\mathrm{Sr}$ and the solid surfaces, regardless of $\mathrm{pH}$ conditions and sorbent. The results revealed significant implications for the migration potential of $\mathrm{Co}$ and $\mathrm{Sr}$ in the environment, because the formation of outer-sphere Co complexes on clay mineral surfaces at low $\mathrm{pH}$, and of $\mathrm{Sr}$ complexes at any $\mathrm{pH}$, regardless of the clay type, suggested that major cations, such as $\mathrm{Mg}$ and $\mathrm{Ca}$, might be able to effectively displace these metal ions from sorption sites, resulting in increased metal ion mobility. In contrast, at high $\mathrm{pH}$, Co forms co-precipitates, making it difficult for Co to be displaced by competing cations, significantly reducing Co mobility (Chen and Hayes 1999). Investigation of the nature of surface complexes formed on Ni uptake onto montmorillonite revealed the formation of $\mathrm{Ni}$ inner-sphere mononuclear surface complexes located at the edges of montmorillonite platelets, and thus heavy metals binding to edge sites is a possible sorption mechanism for dioctahedral smectites. The diffusion of $\mathrm{Ni}$ atoms into the montmorillonite structure was not the dominant uptake mode and the formation of new Ni nucleation products with time might be excluded. Data analysis revealed that the surface complexes either became more ordered with time or that the $\mathrm{Ni}-\mathrm{Al}$ coordination numbers slightly increased with increasing reaction time. They concluded that molecular-level information was crucial for improving mechanistic models on the long-term fate of heavy metal in the geosphere, because the attachment of metal ions specifically bound to clay mineral surfaces can severely reduce their bioavailability and mobility in soil and water environments (Daehn et al. 2003).

We hereby sum up some significant contributions made in the adsorption of dyes using clay materials, highlighting specifically the efficiency of these materials in removing dyes from waste and wastewater. The present work aims to summarize some examples of clay materials used in their raw and/or modified/activated forms as adsorbents for dyes from aqueous solutions or suspensions. We further analyse critically their adsorption properties and the pitfalls of the investigations studied so far.

\section{Some types of clay materials and their uses}

Clays are distinguished from other fine-grained soils by differences in size and mineralogy. Silts, which are finegrained soils that do not include clay minerals, tend to have larger particle sizes than clays, but there is some degree of overlap in both particle size and other physical properties and there are many naturally occurring deposits which include silts and also clay. The distinction between silt and clay varies by discipline. Geologists and soil scientists usually consider the separation to occur at a particle size of $2 \mu \mathrm{m}$ (clays being finer than silts); sedimentologists often use 4-5 $\mu \mathrm{m}$ and colloid chemists use $1 \mu \mathrm{m}$ (Guggenheim and Martin 1995).

Depending on the academic source, there are three or four main groups of clays: kaolinite, montmorillonitesmectite, illite and chlorite. Kaolinite group includes the mineral kaolinite, dickite, halloysite and nacrite. The smectite group includes pyrophyllite, talc, vermiculite, sauconite, saponite, nontronite and montmorillonite. The illite group includes the clay micas. Illite is the only common mineral (Jaafar 2006). Chlorites are not always considered clay; sometimes they are classified as a separate group within the phyllosilicates. There are approximately 30 different types of "pure" clays in these categories, but most "natural" clays are mixtures of these different types, along with other weathered minerals. Varve (or varved clay) is clay with visible annual layers, formed by seasonal differences in erosion and organic content. This type of deposit is common in former glacial lakes. When glacial lakes are formed, there is very little movement of the water that makes the lake and these eroded soils settle on the lake bed. This allows such an even distribution on the different layers of clay. Quick clay is a unique type of marine clay 
indigenous to the glaciated terrains of Norway, Canada, Northern Ireland, and Sweden. It is a highly sensitive clay, prone to liquefaction, which has been involved in several deadly landslides (Bailey 1980).

These differences among the clays provide an opportunity to investigate the impact of structure and layer charge on metal ion coordination to permanent charge sites. In addition, this choice of minerals provided various arrangements of aluminol and silanol surface hydroxyl sites (Chen and Hayes 1999).

\section{Bentonite}

Bentonite is an absorbent aluminium phyllosilicate, which is essentially impure clay consisting mostly of montmorillonite. There are different types of bentonite, each named after the respective dominant element, such as potassium $(\mathrm{K})$, sodium $(\mathrm{Na})$, calcium $(\mathrm{Ca})$ and aluminium $(\mathrm{Al})$. Experts debate a number of nomenclatorial problems with the classification of bentonite clays. Bentonite is usually formed from weathering of volcanic ash, most often in the presence of water. However, the term bentonite, as well as a similar clay called tonstein, has been used to describe clay beds of uncertain origin (Odom 1984). Bentonites have excellent rheological and absorbent properties (Murray 2002). For industrial purposes, two main classes of bentonite exist: sodium and calcium bentonite. Sodium bentonite expands when wet, absorbing as much as several times its dry mass in water. Because of its excellent colloidal properties (Odom 1984), it is often used in drilling mud for oil and gas wells and for geotechnical and environmental investigations. Calcium bentonite is a useful adsorbent of ions in solution (Lagaly 1995), as well as fats and oils, and is a main active ingredient of fuller's earth, probably one of the earliest industrial cleaning agents (Robertson 1986). Calcium bentonite may be converted to sodium bentonite (termed sodium beneficiation or sodium activation) to exhibit many of sodium bentonite's properties by a process known as "ion exchange" (patented in 1935 by Germans: U. Hofmann and K. Endell). Bentonites are environmentally safe providing dust abatement procedures which are used in processing and handling (Murray 2002).

Bentonite also has the interesting property of adsorbing relatively large amounts of protein molecules from aqueous solutions. Therefore, it is uniquely useful in the process of wine making, where it is used to remove excessive amounts of protein from white wines. Were it not for this use of bentonite, many or most white wines would precipitate undesirable flocculent clouds or hazes upon exposure to warmer temperatures as these proteins become denatured. It also has the incidental use of inducing more rapid clarification of both red and white wines. Bentonite can also be used as a desiccant due to its adsorption properties.
Bentonite desiccants have been successfully used to protect pharmaceutical, nutraceutical and diagnostic products from moisture degradation and extend shelf life. In fact, in most common packaging environments, bentonite desiccants offer a higher adsorption capacity than silica gel desiccants. Bentonite complies with the FDA for contact with food and drugs (Food and Drug Administration 2011).

As far as adsorptive properties are concerned, bentonite clay has an overall neutral charge; it has an excess negative charge on its lattice and is characterized by a three-layer structure with two silicate layers enveloping an aluminate layer. This arises from the partial replacement of tetravalent silica with trivalent aluminium that leads to the replacement of trivalent aluminium with divalent calcium. Since opposite charges attract, the negatively charged surface lattice of the bentonite clay may have an affinity for cationic dye. Thus, it could be assumed that bentonite clay may have a greater capacity to adsorb cationic dye as it exhibited high removal of cationic Basic Blue 9 and Thioflavin T dyes (Ramakrishna and Viraraghavan 1997). Bentonite has been used to remove a number of chemical species: amines (Breen 1991); organic pigments $(\beta$ carotenes) (Gonzalez-Pradas et al. 1991); cations (Ni, Zn), phenol and ketones (Stockmeyer and Kruse 1991); phosphates (Gonzalez-Pradas et al. 1992); pesticides (GonzalezPradas et al. 1993); chlorophyll (Gonzalez-Pradas et al. 1994); and non-ionic contaminants (Smith and Jaffe 1994; Espantaleón et al. 2003). Bentonite has proven to be a promising economic material for the removal of dyes due to its abundance and availability (Bellir et al. 2010).

\section{Kaolinite}

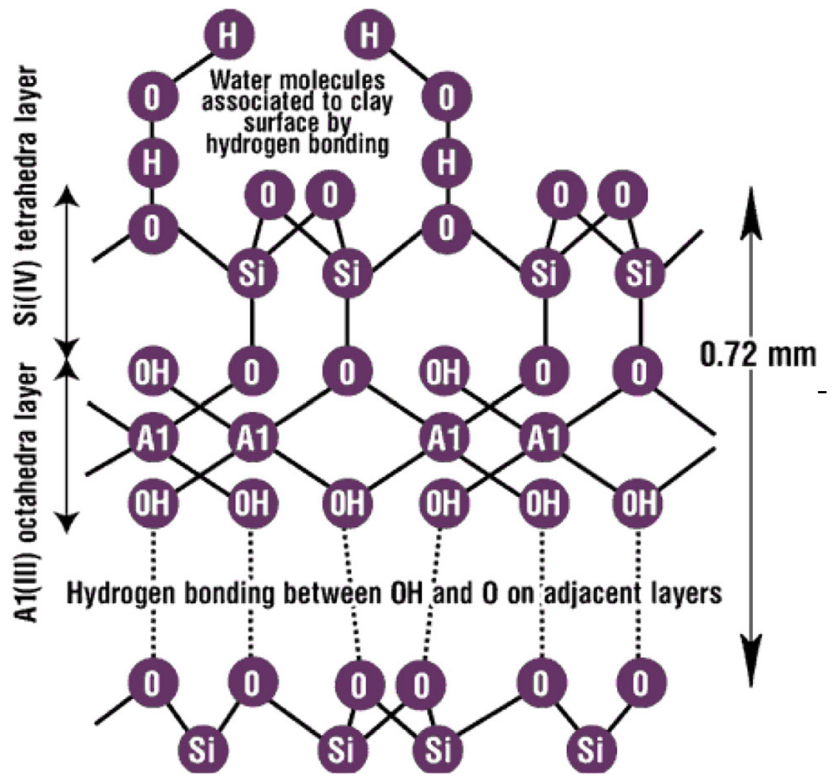

The kaolinite group includes the dioctahedral minerals kaolinite, dickite, nacrite, and halloysite and the 
trioctahedral minerals antigorite, chamosite, chrysotile and cronstedite, with a formula of $\mathrm{Al}_{2} \mathrm{Si}_{2} \mathrm{O}_{5}(\mathrm{OH})_{4}$ (Moore and Reynolds 1997). Kaolin is a soft, white plastic clay consisting mainly of the mineral kaolinite which is a hydrated aluminium silicate $\mathrm{Al}_{2} \mathrm{Si}_{2} \mathrm{O}_{5}(\mathrm{OH})_{4}$ (Murray 2002). The different minerals are polymorphs, i.e. they have the same chemistry but different structures. The general structure of the kaolinite group is composed of silicate sheets $\left(\mathrm{Si}_{2} \mathrm{O}_{5}\right)$ bonded to aluminium oxide/hydroxide layers $\left(\mathrm{Al}_{2}(\mathrm{OH})_{4}\right)$ called gibbsite layers (Moore and Reynolds 1997), which is a layered silicate mineral with one tetrahedral sheet linked through oxygen atoms to one octahedral sheet of alumina octahedra (Deer et al. 1992). The primary structural unit of this group is a layer composed of one octahedral sheet condensed with one tetrahedral sheet. In the dioctahedral minerals, the octahedral sites are occupied by aluminium, while in the trioctahedral minerals, these sites are occupied by magnesium and iron. Kaolinite and halloysite are singlelayer structures. Kaolinite, dickite and nacrite occur as plates; halloysite, which can have a single layer of water between its sheets, occurs in a tubular form. Kaolinite is a non-swelling clay (Moore and Reynolds 1997; Chen and Hayes 1999).

Rocks that are rich in kaolinite are known as kaolin or china clay (Pohl 2011). It is formed by the alteration of feldspar and muscovite. Kaolin deposits are classified as either primary or secondary. Primary kaolins result from residual weathering or hydrothermal alteration and secondary kaolins are sedimentary in origin. Kaolin is an important industrial mineral, which is used in many industrial applications (Murray 2002). The kaolinite group clay undergoes a series of phase transformations upon thermal treatment in air at atmospheric pressure. Endothermic dehydroxylation (or alternatively, dehydration) begins at $550-600{ }^{\circ} \mathrm{C}$ to produce disordered metakaolin, $\mathrm{Al}_{2} \mathrm{Si}_{2} \mathrm{O}_{7}$, but continuous hydroxyl loss $(-\mathrm{OH})$ is observed up to $900{ }^{\circ} \mathrm{C}$ and has been attributed to gradual oxolation of the metakaolin (Bellotto et al. 1995).

The fact that kaolinite has heterogeneous surface charge is well known. The basal surface of kaolinites is believed to carry a constant structural charge, which is attributed to the isomorphous substitution of $\mathrm{Si}^{4+}$ by $\mathrm{Al}^{3+}$. The charge on the edges is due to protonation/deprotonation of surface hydroxyl groups and therefore depends on the solution $\mathrm{pH}$ (Zhou and Gunter 1992). Kaolinite is the least reactive clay (Suraj et al. 1998). However, its high pH dependency enhances or inhibits the adsorption of metals according to the $\mathrm{pH}$ of the environment (Mitchell 1993), and this metal adsorption is usually accompanied by the release of hydrogen $\left(\mathrm{H}^{+}\right)$ions from the edge sites of the mineral. Adsorption may also take place on the flat exposed planes of the silica and the alumina sheets (Spark et al. 1995). Kaolin is an environmentally safe material with no adverse health problems as long as the fine particle dust is controlled.

\section{Montmorillonite/smectites}

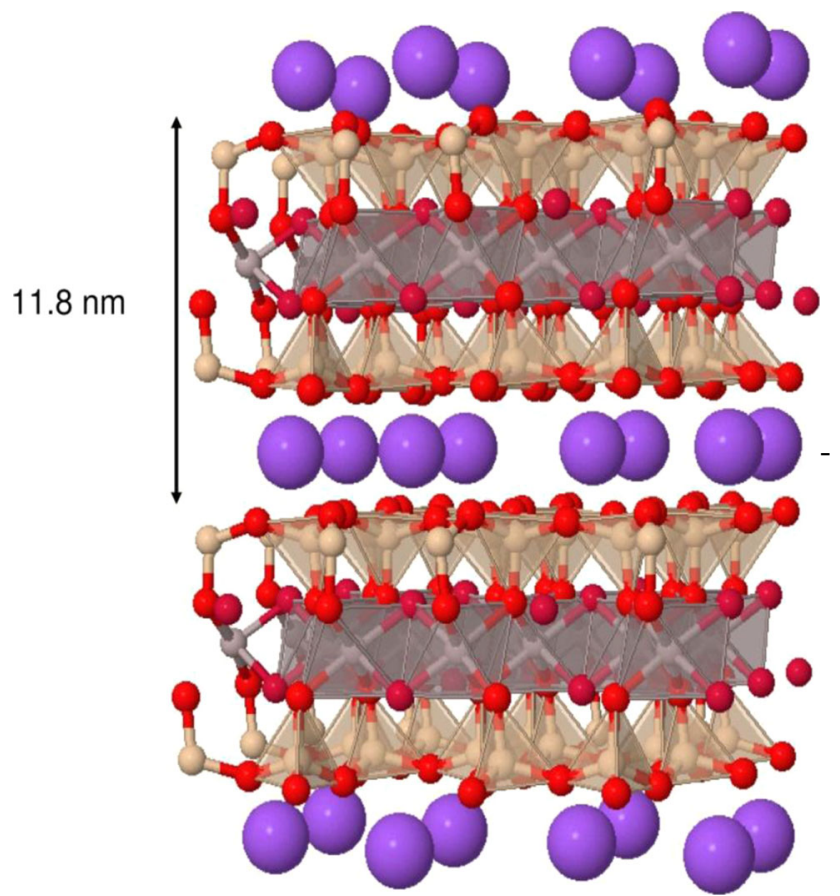

Montmorillonite is a very soft phyllosilicate mineral that typically forms in microscopic crystals, forming clay (Jaafar 2006). Montmorillonite, a member of the smectite family, has 2:1 expanding crystal lattice. The smectite group refers to a family of non-metallic clays primarily composed of hydrated sodium calcium aluminium silicate, a group of monoclinic clay-like minerals with general formula $(\mathrm{Ca}, \mathrm{Na}, \mathrm{H})(\mathrm{Al}, \mathrm{Mg}, \mathrm{Fe}, \mathrm{Zn})_{2}(\mathrm{Si}, \mathrm{Al}) 4 \mathrm{O}_{10}(\mathrm{OH})_{2-}$ $n \mathrm{H}_{2} \mathrm{O}$ (Grim 1962). Chemically, it is hydrated sodium calcium aluminium magnesium silicate hydroxide $(\mathrm{Na}, \mathrm{Ca})_{x}(\mathrm{Al}, \mathrm{Mg})_{2}\left(\mathrm{Si}_{4} \mathrm{O}_{10}\right)(\mathrm{OH})_{2} \cdot n \mathrm{H}_{2} \mathrm{O}$. Potassium, iron and other cations are common substitutes and the exact ratio of cations varies with source (Jaafar 2006). The basic structural unit is a layer consisting of two inward-pointing tetrahedral sheets with a central alumina octahedral sheet. The layers are continuous in the length and width directions, but the bonds between these layers are weak and have excellent cleavage, allowing water and other molecules to enter between the layers causing expansion in the highness direction. Isomorphous substitution gives the various types of smectite and causes a net permanent charge balanced by cations in such a manner that water may move between the sheets of the crystal lattice, giving a reversible cation exchange and very plastic properties (Grim 1962).

Montmorillonite's water content is variable; increasing greatly in volume when it absorbs water (montmorillonite 
swells with the addition of water similar to other clays) and it is the main constituent of the volcanic ash weathering product, bentonite. However, some montmorillonites expand considerably more than other clays due to water penetrating the interlayer molecular spaces and concomitant adsorption. The amount of expansion is largely due to the type of exchangeable cation contained in the sample. The presence of sodium as the predominant exchangeable cation can result in the clay swelling to several times its original volume. Hence, sodium montmorillonite has come to be used as the major constituent in non-explosive agents for splitting rock in natural stone quarries to limit the amount of waste, or for the demolition of concrete structures where the use of explosive charges is unacceptable (Jaafar 2006; Chen and Hayes 1999).

The particles are plate shaped with an average diameter of approximately $1 \mu \mathrm{m}$. The particle thickness is extremely small ( $\sim 1 \mathrm{~nm}$ ) (Jaafar 2006). Smectites possess a large specific area and a high structural charge (up to 1000 meq $\mathrm{kg}^{-1}$ ), imparting them with important sorptive properties. The uptake mechanisms of metal ions onto smectites depends on ionic strength, $\mathrm{pH}$ and the type of ion being adsorbed (Daehn et al. 2003).

\section{Sepiolite/palygorskite}

Sepiolite and palygorskite are natural clay minerals consisting of magnesium hydro silicate which belongs to the group of silicates (Espantaleón et al. 2003). Although both minerals are $\mathrm{Mg}$ silicates, palygorskite exhibits more structural diversity and has less $\mathrm{Mg}$ and more $\mathrm{Al}$ than sepiolite. They are fibrous clay minerals with the ideal formula of $\mathrm{Si}_{12} \mathrm{Mg}_{8} \mathrm{O}_{30}(\mathrm{OH})_{4}\left(\mathrm{H}_{2} \mathrm{O}\right)_{4} \cdot 8 \mathrm{H}_{2} \mathrm{O}$ for sepiolite and $\mathrm{Si}_{8} \mathrm{Mg}_{5} \mathrm{O}_{20}(\mathrm{OH})_{2}\left(\mathrm{H}_{2} \mathrm{O}\right)_{4} \cdot 4 \mathrm{H}_{2} \mathrm{O}$ for palygorskite (Cailleres and Henin 1961). Their fibrous structure is formed as a result of storage of tetrahedral and octahedral oxide layers which has canal cavities along the fibber; this peculiar structure provides high sorption capacity (Espantaleón et al. 2003). The structures of both minerals are similar in that the tetrahedral pointing in the same direction form 2:1 ribbons that extend in the direction of the a-axis and have an average b-axis width of three linked tetrahedral chains in sepiolite and two linked chains in palygorskite (Singer 1989). When dispersed in water, these elongated crystals are inert and non-swelling and form a random lattice capable of trapping liquid and providing excellent thickening, suspending and gelling properties. These clays do not flocculate with electrolytes and are stable at high temperatures, which make them uniquely applicable for many uses (Murray 2002). Furthermore, because of their natural hollow brick-like structure, they have great potential for the retention of micro-pollutants including heavy metal cations and dyes (Cailleres and
Henin 1961). Rectangular channels, which contain some exchangeable $\mathrm{Ca}$ and $\mathrm{Mg}$ cations and zeolitic water, lie between the ribbons and molecules of bound water lie at the edges of the ribbons (Liu and Zhang 2007).

Sepiolite has been used to adsorb Methylene Blue (MB) (Aznar et al. 1992); 4,4'-bipyridyl (Akyuz et al. 1993a); benzidine (Akyuz et al. 1993b), ammonium and ammonia (Bernal and Lopez-Real 1993); tetrahydropyran, tetrahydrofuran and 1,4-dioxan (Breen 1994).

\section{Clay materials used as adsorbents for dye treatment}

\section{Bentonite}

The most common and most effective type of clay used in water purification is bentonite which is an adsorbent and is generally impure clay consisting mostly of montmorillonite, although some may consist of the rare clay minerals, i.e. beidellite, saponite, hectorite and nontronite. The structure of montmorillonite is a gibbsite layer sandwiched between two silica sheets to form the structural unit (Tunega et al. 2002; Zakaria et al. 2009). The substitutions are mainly within the octahedral layer $\left(\mathrm{Mg}^{2+}, \mathrm{Fe}^{2+}\right)$ and to a much less extent within the silicate layer $\left(\mathrm{Al}^{3+} / \mathrm{Si}^{4+}\right)$. The chemical composition of the clay mineral is based on a hydroxyl-aluminosilicate framework. The crystal structures of the clay minerals are formed by a combination of sheets of silica tetrahedral and alumino octahedral. Part of the trivalent $\mathrm{Al}$ is substituted by divalent $\mathrm{Mg}$ or $\mathrm{Fe}$ in some cases. In such cases, substitution is accompanied by the addition of alkaline metals such as $\mathrm{Na}$ and $\mathrm{K}$ or alkaline earth metals such as $\mathrm{Mg}$ and $\mathrm{Ca}$ to provide charge balance (Zakaria et al. 2009). The adsorption behaviour of organophilic bentonites in contact with aqueous solutions of organic compounds was studied by Stockmeyer. Phenol, aniline, nitroethane, diethyl ketone, ethoxy acetic acid, maleic acid and hexadecyl pyridinium bromide were used as test substances. The investigated organoclays vary in the degree of their total cation exchange capacity (CEC) exchanged by organic counter ions (Stockmeyer 1991).

The ability of bentonite to remove malachite green (MG) from aqueous solutions was investigated for different adsorbate concentrations by varying the amount of adsorbent, shaking time, $\mathrm{pH}$ and temperature. Adsorption of the dye was studied by batch technique and it was observed that $>90 \%$ of dye removal was achieved by using $0.05 \mathrm{~g}$ of bentonite. Equilibrium between the dye and the bentonite was attained within $10 \mathrm{~min}$. Three consecutive steps were involved in the removal of dye from water on bentonite. First, the adsorbate species migrated from the bulk liquid phase to the outer surface of adsorbent particles (film 


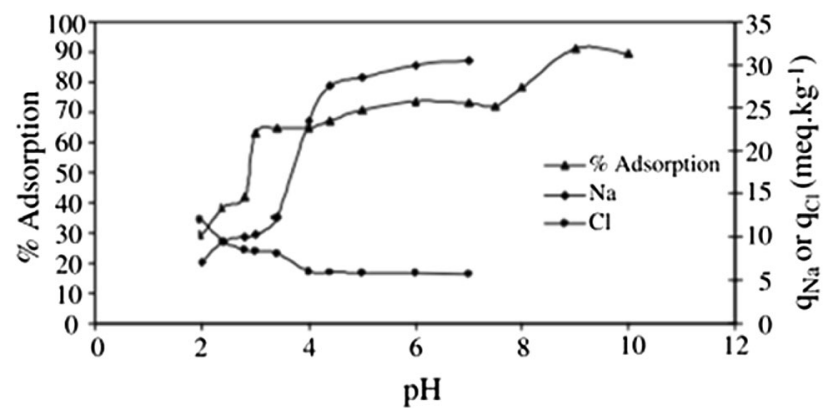

Fig. 1 Effect of $\mathrm{pH}$ on the adsorption of malachite green oxalate onto bentonite and the relationship between the net negative/positive surface charge of the clay and $\mathrm{pH}$ of the solution $(I=0.01 \mathrm{M} \mathrm{NaCl})$ (Tahir and Naseem 2006)

diffusion). Secondly, the dye species moved within the micro- and macro-pores of adsorbent particles (pore diffusion). Thirdly, the reaction of adsorbate-adsorbent species took place on the surface.

The influence of $\mathrm{pH}$ on the dye adsorption onto bentonite was studied while the dye concentration, shaking time and amount of bentonite were fixed at $56.8 \mathrm{mg} \mathrm{cm}^{-3}$, $10 \mathrm{~min}$ and $0.05 \mathrm{~g}$, respectively. The variation of $\mathrm{MG}$ adsorption on bentonite over a $\mathrm{pH}$ range of 2.0-10.0 revealed that the adsorption of the dye increased from $29 \%$ to $91 \%$ with an increase in $\mathrm{pH}$ of the solution from 2.0 to 9.0 and then remained almost constant (Fig. 1). The adsorption of these charged dye groups onto the adsorbent surface was primarily influenced by the surface charge on the adsorbent, which was in turn influenced by the solution $\mathrm{pH}$. The $\mathrm{pH}_{\mathrm{pzc}}$ (pH at point of zero charge) value for bentonite was 2.2. At $\mathrm{pH}$ values below pzc, the clay had net positive charge and would, therefore, be prone to electrostatically repel cations. Malachite green is a cationic basic dye as denoted by the presence of positive nitrogen ion in its structure. On dissolution, the oxalate ion enters the aqueous solution ensuring that the dye has an overall positive charge. The positive charge on the cationic dye ensured that it was attracted by an anionic adsorbent. The adsorption was maximum at $\mathrm{pH} 9$, with almost $91 \%$ removal of the dye; so at high $\mathrm{pH}$, the solution in contact with the basal oxygen surface of the tetrahedral sheet will contain excess hydroxyls and thus the surface exhibited a CEC (Tahir and Naseem 2006).
The influence of temperature on dye adsorption was investigated over the concentration ranges of 50, 70, 90 and $140 \mathrm{~g} \mathrm{~cm}^{-3}$ at $298,308,318$ and $328 \mathrm{~K}$ under the optimized conditions of $10 \mathrm{~min}$ shaking time, $0.05 \mathrm{~g}$ of adsorbent and a $\mathrm{pH}$ of 5.6. Increase in temperature reduced the adsorption capacity of bentonite due to the enhancement of the desorption step in the mechanism. The mean energy of adsorption was determined over the same range of temperatures and was found to be between 1.00 and 1.13 $\mathrm{kJ} \mathrm{mol}^{-1}$ corresponding to physical adsorption. The positive values of $\Delta H^{\circ}$ and $\Delta S^{\circ}$ suggested endothermic reaction, while the negative values of free energy change $\left(\Delta G^{\circ}\right)$ indicated that the adsorption was spontaneous (Table 1). The positive values of $\Delta S^{\circ}$ suggested the increased randomness at the solid-solution interface during desorption of MG oxalate on bentonite. During desorption of the dye, the adsorbed solvent molecules, which were displaced by the adsorbate species, gained more translational entropy than that lost by the adsorbate ions, thus allowing the prevalence of randomness in the system (Tahir and Naseem 2006).

Ehssan and co-workers studied the thermodynamics of adsorption of some dyes on Iraqi bentonite modified clay. The $\mathrm{pH}$ of the dye solution played an important role in the whole adsorption process and particularly on the adsorption capacity. The variation of Fast Green (FG) and crystal violet $(\mathrm{CV})$ adsorption on modified clay over a broad range of $\mathrm{pH}$ showed that the adsorption of $\mathrm{CV}$ was lower at $\mathrm{pH}<7$, but increased to higher values at $\mathrm{pH}>7$, while the adsorption of FG was lower at $\mathrm{pH}>7$, but increased to higher values at $\mathrm{pH}<7$ (Fig. 2).

The mechanism of colour removal was by the migration of the dye molecule from the solution to the adsorbents particle and diffusion through the surface. The equilibrium time was reached within $30 \mathrm{~min}$ of operation for Iraqi bentonite-modified clay and the adsorption capacity was constant thereafter for both adsorbates in a $60 \mathrm{~min}$ reaction time. The thermodynamic parameters measured over a temperature range of $293-333 \mathrm{~K}$ showed negative $\Delta G$ value $\left(-1.94 \mathrm{~kJ} \mathrm{~mol}^{-1}\right)$ for $\mathrm{CV}$, indicating its feasibility and spontaneous nature for adsorption on the modified clay. The change in enthalpy $(\Delta H)$ for $\mathrm{CV}$ was found to be positive $\left(3.38 \mathrm{~kJ} \mathrm{~mol}^{-1}\right)$, confirming the endothermic

Table 1 Thermodynamic parameters for the adsorption of malachite green onto bentonite (Tahir and Naseem 2006)

\begin{tabular}{|c|c|c|c|c|c|c|}
\hline \multirow{2}{*}{$\begin{array}{l}\text { Concentration of malachite } \\
\text { green oxalate }\left(\mathrm{mg} \mathrm{cm}^{-3}\right)\end{array}$} & \multirow[t]{2}{*}{$\Delta H^{\circ}\left(\mathrm{kJ} \mathrm{mol}{ }^{-1}\right)$} & \multirow[t]{2}{*}{$\Delta S^{\circ}\left(\mathrm{kJ} \mathrm{mol}^{-1} \mathrm{~K}^{-1}\right)$} & \multicolumn{4}{|c|}{$-\Delta G^{\circ}\left(\mathrm{kJ} \mathrm{mol}^{-1}\right)$} \\
\hline & & & $298 \mathrm{~K}$ & $308 \mathrm{~K}$ & $318 \mathrm{~K}$ & $328 \mathrm{~K}$ \\
\hline 50 & 0.0134 & 0.0336 & 11.0054 & 10.6695 & 10.336 & 9.9976 \\
\hline 70 & 0.0206 & 0.0088 & 2.8952 & 2.8063 & 2.7174 & 2.6285 \\
\hline 90 & 0.0210 & 0.0065 & 2.1053 & 2.0405 & 1.9757 & 1.9109 \\
\hline 140 & 0.0295 & 0.0243 & 8.0095 & 7.7662 & 7.5229 & 7.2796 \\
\hline
\end{tabular}




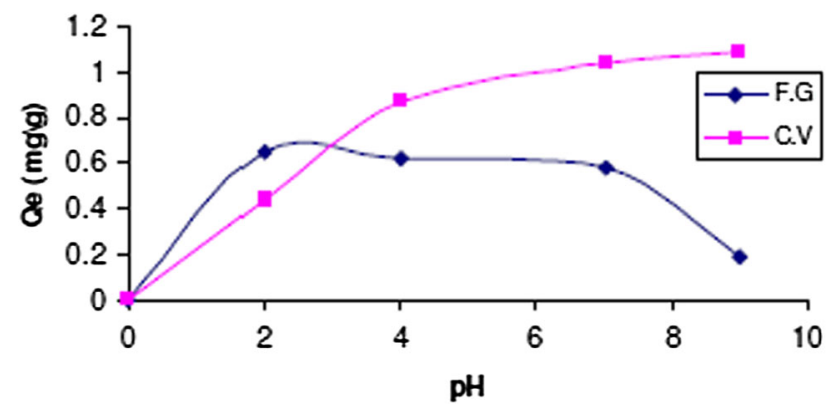

Fig. 2 Effect of $\mathrm{pH}$ on the removal of colour from aqueous solution of crystal violet and Fast Green (Ehssan et al. 2011)

nature of adsorption. However, the negative $\Delta H$ value for FG indicated the exothermic nature of the adsorption process. The maximum and minimum adsorption values were obtained at $3 \mathrm{ppm}$ and $12 \mathrm{ppm}$ concentrations, respectively, for FG, while the maximum and minimum adsorption values were obtained at $6 \mathrm{ppm}$ and $12 \mathrm{ppm}$ concentrations, respectively, for $\mathrm{CV}$. The difference in \% adsorption of these dyes on the surface of Iraqi bentonitemodified clay may be due to the presence of more or less irregular and defective edges. These played a significant role in the adsorption phenomenon, as these edges struck the unsaturated part of the dyes and accelerated the removal of dye molecules (Table 2).

The adsorption capacity of $\mathrm{CV}$ was much higher than of FG, as observed when the uptake of FG decreased with an increase in temperature up to $50{ }^{\circ} \mathrm{C}$. This difference was related to the higher affinity of $\mathrm{CV}$ for the adsorbent surface than FG and may also be attributed to a tendency for the dye molecules to escape from the solid phase of the modified clay to the liquid phase of dye with an increase in temperature of the solution. Thermal treatment increased the adsorption of Iraqi bentonite-modified clay and the manufactured powder presented a homogeneous fixation on the clay surface (Ehssan et al. 2011).

The effect of the contact time on the removal of MB from aqueous solutions using acid-activated Algerian

Table 2 Percent adsorption and distribution ratio (Kd) of FG and CV by modified clay (Ehssan et al. 2011)

\begin{tabular}{llllll}
\hline Dyes conc. p.p.m & \multicolumn{2}{l}{ Fast green } & & \multicolumn{2}{c}{ Crystal violet } \\
\cline { 2 - 3 } \cline { 6 - 7 } & \% Adso. & Kd & & $\%$ Adso. & Kd \\
\hline 3 & 97 & 38 & 87 & 138 \\
6 & 77 & 31 & 90 & 144 \\
9 & 76 & 30 & 87 & 139 \\
12 & 68 & 27 & 81 & 129 \\
15 & 73 & 29 & 83 & 132 \\
18 & 72 & 29 & 84 & 135 \\
21 & 74 & 30 & 85 & 136 \\
\hline
\end{tabular}

bentonite revealed that the MB adsorption was fast at the initial stage of the contact period, but became slower near equilibrium (120th-200th $\mathrm{min}$ ). This phenomenon was due to the fact that a large number of vacant surface sites were available for adsorption at the initial stage. The remaining vacant surface sites were difficult to occupy close to equilibrium, probably due to the slow pore diffusion of the solute molecules on the solid and the bulk phase. The increase of the initial concentration resulted in substantial increase in the amount of dye retained for the same quantity of bentonite, leading to increase in the amount of MB molecules adsorbed onto the free sites available on the surface of clay particles. However, when all the sites were occupied, the amount of MB molecules adsorbed became constant and there was formation of a monolayer (Bellir et al. 2010).

The removal efficiency of MB was minimum at $\mathrm{pH}=3$ $(55.48 \%)$ and reached maximum $(91.65 \%)$ for a $\mathrm{pH}$ value of 10 in the first $5 \mathrm{~min}$ of the adsorption process. The dye uptake was found to be relatively small at low $\mathrm{pH}$ values; however, increase in the $\mathrm{pH}$ values by $4-5$ units increased the rate of adsorption considerably. The effect of $\mathrm{pH}$ was reduced towards the end of the adsorption process (after 90 min of shaking time). At acidic $\mathrm{pH}, \mathrm{H}^{+}$competed with dye ions for the adsorption sites on the bentonite surface, thereby inhibiting the adsorption of dye at low $\mathrm{pH}$. However, in alkaline environment, there were possibly more negative charges present on the bentonite surface due to the deprotonation of the surface hydroxyl site $(\mathrm{M}-\mathrm{OH})$, such as alumina and silica $(\mathrm{Al}-\mathrm{OH}$ and $\mathrm{Si}-\mathrm{OH})$; thus, the number of ionizable sites on bentonite increased. The $\mathrm{pH}$ of the solution played an important role in the retention of MB, and thus the basic environment was the most suitable for the removal of MB (Bellir et al. 2010).

The adsorption capacities of the clay increased with increasing contact time and initial concentration, although it remained constant after $30 \mathrm{~min}$ for 10,20 and $30 \mathrm{mg} \mathrm{L}^{-1}$ (Fig. 3). The acid-activated Algerian bentonite clay had a unique affinity towards $\mathrm{MB}$ as well as a relatively high mobility of this dye in aqueous solution (Bellir et al. 2010).

Natural bentonite, modified by thermal activation (TA), acid activation (AA) and combined acid and thermal activation (ATA) was used for the removal of diazo dye. The Congo Red (CR) adsorption increased with increase in contact time, with $>95 \%$ dye removal attained using modified bentonites in $6 \mathrm{~h}$. The adsorption rate was very high in the first $2 \mathrm{~h}$, leading to $96.65,92.75$ and $91.62 \%$ of CR removal using bentonite modified by ATA, AA and TA, respectively. On comparing these results to those of raw bentonite, approximately $20 \% \mathrm{CR}$ removal was enhanced by the ATA and AA bentonites in $4 \mathrm{~h}$ (Fig. 4a). The relatively high $\mathrm{CR}$ removal was attributed to the availability of a large number of vacant sites for CR 

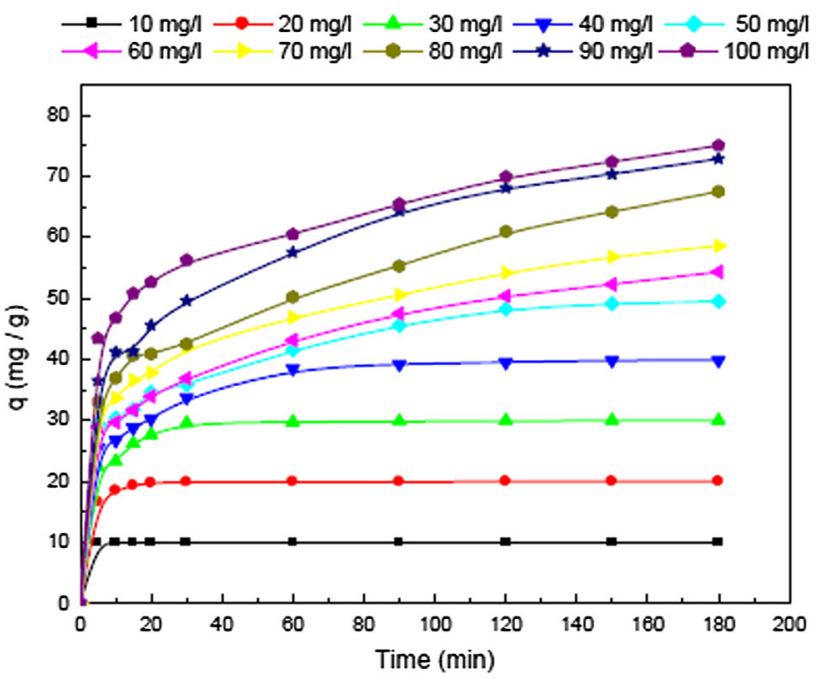

Fig. 3 Effect of the initial concentration on the adsorption of Methylene Blue at $\mathrm{pH} \approx 4.7$ (Bellir et al. 2010)

adsorption. CR adsorption increased with the initial dye concentration up to $1000 \mathrm{mg} \mathrm{L}^{-1}$ at the given adsorption conditions: $\mathrm{T}\left(25^{\circ} \mathrm{C}\right), \mathrm{pH}(7.0)$, contact time $(24 \mathrm{~h}), \mathrm{CR}$ concentration $\left(1000 \mathrm{mg} \mathrm{L}^{-1}\right)$ and bentonite dosage (10 $\mathrm{g} \mathrm{L}^{-1}$ ). ATA bentonite had the highest increase in adsorption capacity of $74.5 \mathrm{mg} \mathrm{g}^{-1}$, followed by AA bentonite $\left(61.5 \mathrm{mg} \mathrm{g}^{-1}\right)$ and $\mathrm{TA}$ bentonite $\left(52.6 \mathrm{mg} \mathrm{g}^{-1}\right)$, which were significantly comparable to raw bentonite (RB) (20.8 $\mathrm{mg} \mathrm{g}^{-1}$ ) (Fig. 4b) (Toor and Jin 2012).

The overall increase in adsorption capacity was $258 \%$ by ATA, $196 \%$ by AA and $153 \%$ by TA. The CR adsorption capacity of the bentonites followed the order: ATA $>$ AA $>$ TA $>$ RB. The CR adsorption on all the bentonite samples did not show a plateau suggesting that there was no formation of monolayer on the surface of the adsorbents. The steady increase in the adsorption with the initial dye concentration indicated that bentonite had very high potential for CR removal. The CR removal increased as the adsorbent dosage increased from ATA bentonite (88\%), AA bentonite $(74 \%)$ and TA bentonite $(63 \%)$ to nearly $100 \%$. CR adsorption increased gradually up to 14 with $2 \mathrm{~g} \mathrm{~L}^{-1}$ of bentonite dosage, but further increase in bentonite dosage beyond $14 \mathrm{~g} \mathrm{~L}^{-1}$ exhibited no significant improvement in dye removal due to the attainment of equilibrium between the adsorbate and adsorbent under the experimental condition. Compared to ATA bentonite, a low equilibrium adsorption of $16 \mathrm{~g} \mathrm{~L}^{-1}$ was achieved by AA and TA bentonites. The increase in CR adsorption with $20 \mathrm{~g} \mathrm{~L}^{-1}$ of raw bentonite from $58 \%$ to nearly $100 \%$ was attributed to the increase in surface area of micropores and the increase in availability of vacant adsorption sites (Toor and Jin 2012).

The colour of CR solution changed from red to blue in the presence of inorganic acids in a $\mathrm{pH}$ range of $2-4$. Under
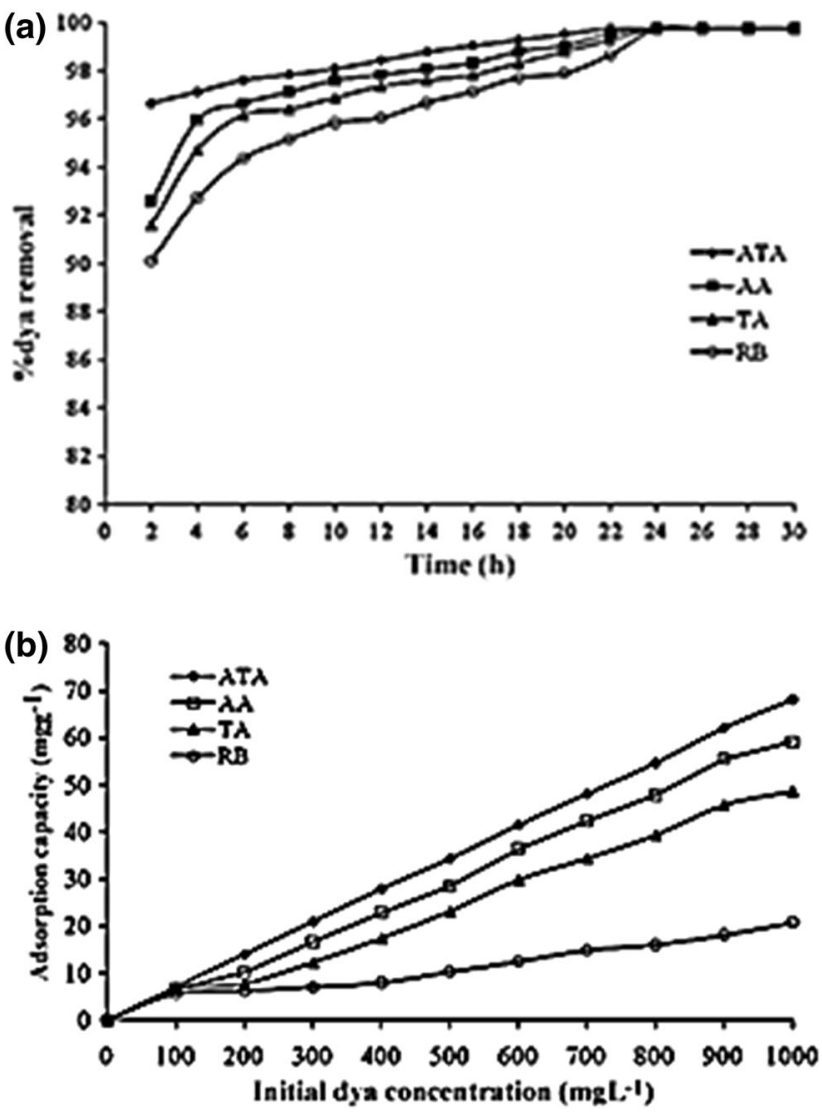

Fig. 4 a Effect of contact time ( $\mathrm{SD} \pm 0.11,0.42,0.26,0.61)$ on $\mathrm{CR}$ adsorption by bentonite modified by ATA, AA, TA and RB, respectively (Toor and Jin 2012). b Effect of initial dye concentration (SD $\pm 0.09,0.23,0.03,0.19$ ) on CR adsorption by bentonite modified by ATA, AA, TA and RB, respectively (Toor and Jin 2012)

alkaline condition, i.e. $\mathrm{pH} 10-12$, the $\mathrm{CR}$ solution remained red, but the red colour was different from the original colour of the solution due to the resonance between charged canonical structures. The chemical structure of bentonite varied with $\mathrm{pH}$, viz., natural bentonite is basic in nature and bears a net negative charge on its surface in the presence of inorganic acids. The transformation in the clay structure resulted in the buildup of net positive charge on the clay surface. The effect of initial $\mathrm{pH}$ of 3, 5, 7, 9 and 11 on the CR adsorption on TA, AA and ATA bentonites revealed that the $\mathrm{pH}$ changes had little impact on the $\mathrm{CR}$ adsorption performance using the raw and modified bentonites. While over $95 \% \mathrm{CR}$ removal was achieved using the three modified bentonites at $\mathrm{pH} 3-11$, a slight decrease in the $\mathrm{CR}$ adsorption was observed at $\mathrm{pH}>10$ attributed to the repulsion between the anionic dye molecules and negatively charged clay particles. The adsorption reactions via CR-activated bentonite systems resulted in a slight increase in the final $\mathrm{pH}$ when the initial $\mathrm{pH}$ was $<5$. On the contrary, a decrease in the final $\mathrm{pH}$ was observed in the CR-bentonite solution in which initial $\mathrm{pH}$ was $8-11$. 
At temperatures of $25,30,40,50$ and $60{ }^{\circ} \mathrm{C}$, there was slight decrease in the $\mathrm{CR}$ adsorption on bentonites modified by ATA, AA and TA as the temperature increased, indicating that preferential adsorption may occur at a low temperature. The slight decrease in the CR adsorption in all the modified bentonites revealed that these adsorption reactions were exothermic and had favourable adsorption at a lower temperature as confirmed by the negative $\Delta H^{\circ}$ values, indicating physisorption (range: -20 to 0 $\mathrm{kJ} \mathrm{mol}^{-1}$ ). The dye molecules were held more strongly by ATA bentonite as indicated by the enthalpy of ATA bentonite which was higher than AA bentonite. The negative values of Gibbs energy indicated spontaneity and feasibility of the adsorption process with high preference of $\mathrm{CR}$ for the modified bentonites. Decrease in randomness at the solid/solution interface was observed as suggested by the negative $\Delta S^{\circ}$ values, and there was no significant change in the internal structure of the adsorbents through CR adsorption onto the modified bentonites. The modification process by thermal and acid activation is a promising approach for enhancement of the adsorption capacity by $150-250 \%$ for removing synthetic dyes over a wide concentration range (Toor and Jin 2012).

Lian and his group studied the adsorption of CR from aqueous solutions onto Ca-bentonite. The removal efficiency of CR onto Ca-bentonite by adsorption was initially rapid and slowed down gradually until it attained equilibrium. The effect of contact time on the percentage of colour removal at various temperatures examined at $100 \mathrm{mg} \mathrm{L}^{-1}$ concentration of $\mathrm{CR}$ showed that the contact time for $\mathrm{CR}$ was $480 \mathrm{~min}$ when the temperatures were between 20 and $40{ }^{\circ} \mathrm{C}$. However, the uptake was very rapid and attained equilibrium in $180 \mathrm{~min}$ at $50{ }^{\circ} \mathrm{C}$, achieving maximum percent removal of $95.92 \%$ at $50{ }^{\circ} \mathrm{C}$ (Fig. 5). Increase in temperature led to increased uptake of CR by Ca-bentonite, implying that the enthalpy change had positive values and the adsorption process was endothermic (Lian et al. 2009).

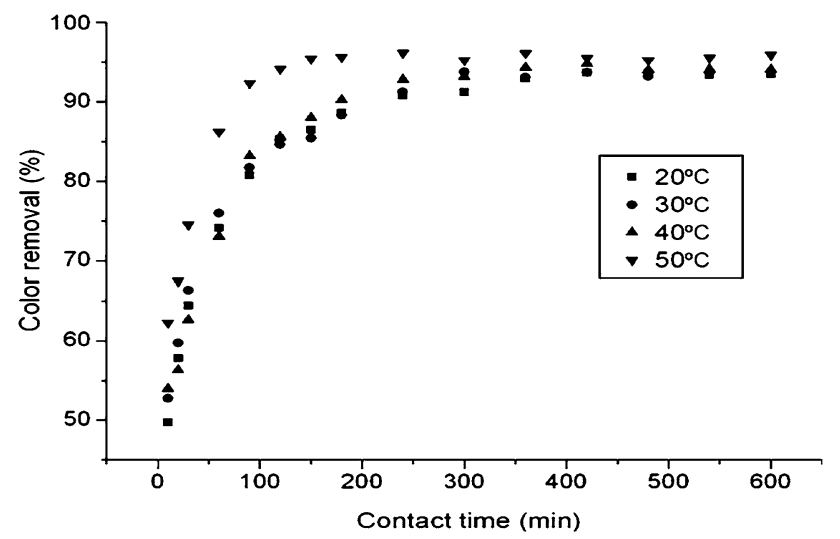

Fig. 5 Effect of agitation time and temperatures on the extent of adsorption (Lian et al. 2009)
The maximum colour removal efficiency occurred at $\mathrm{pH} 5$ $(94.59 \%)$ and the amount of dye adsorbed onto Ca-bentonite did not change significantly in the $\mathrm{pH}$ range 6-10 (Fig. 6). Ca-bentonite can neutralize $\mathrm{H}^{+}$or $\mathrm{OH}^{-}$in acidic or alkaline media and this made the solution tend toward neutral due to its special structural properties, thus neutralizing the acidic $\mathrm{pH}$ of the dye solution. On the other hand, Ca-bentonite has high calcium content; thus, $\mathrm{Ca}^{2+}$ can neutralize the $\mathrm{OH}^{-}$on the surface of Ca-bentonite, which decreased the effect of $\mathrm{pH}$ on the adsorption significantly, i.e. Ca-bentonite can be suitable in wastewater treatment of similar dyestuffs at different $\mathrm{pH}$ values. The amount of dye adsorbed by Ca-bentonite increased from 23.25 to $85.29 \mathrm{mg} \mathrm{g}^{-1}$ at $20^{\circ} \mathrm{C}$ and natural $\mathrm{pH}$ (6.92) of the $\mathrm{CR}$ solution, with increasing initial dye concentration from 50 to $200 \mathrm{mg} \mathrm{L}^{-1}$. A large number of vacant surface sites were available for adsorption during the initial stage of treatment, and after a lapse of time it was difficult to occupy the remaining vacant surface sites, due to repulsive forces between the $\mathrm{CR}$ dye adsorbed on the surface of Ca-bentonite and the solution phase (Lian et al. 2009).

The adsorption process was explicitly highly dependent on the initial concentration of the solution. The negative values of $\Delta G_{\mathrm{o}}$ at different temperatures indicated the feasibility of the process and the spontaneous nature of the adsorption. The adsorption is endothermic as indicated by the positive $\Delta H_{\mathrm{o}}$ value $\left(5.1376 \mathrm{~kJ} \mathrm{~mol}^{-1}\right)$ and is physical in nature. Furthermore, slightly positive $\Delta S_{\mathrm{o}}$ value $(0.0372$ $\mathrm{kJ} \mathrm{mol}^{-1} \mathrm{~K}^{-1}$ ) of the $\mathrm{CR}$ adsorption process indicated an irregular increase of the randomness at the Ca-bentonitesolution interface during adsorption (Lian et al. 2009).

\section{Kaolinite}

The removal of MB from aqueous solution in a batchstirred tank reactor using alginate/polyvinyl alcohol-kaolin

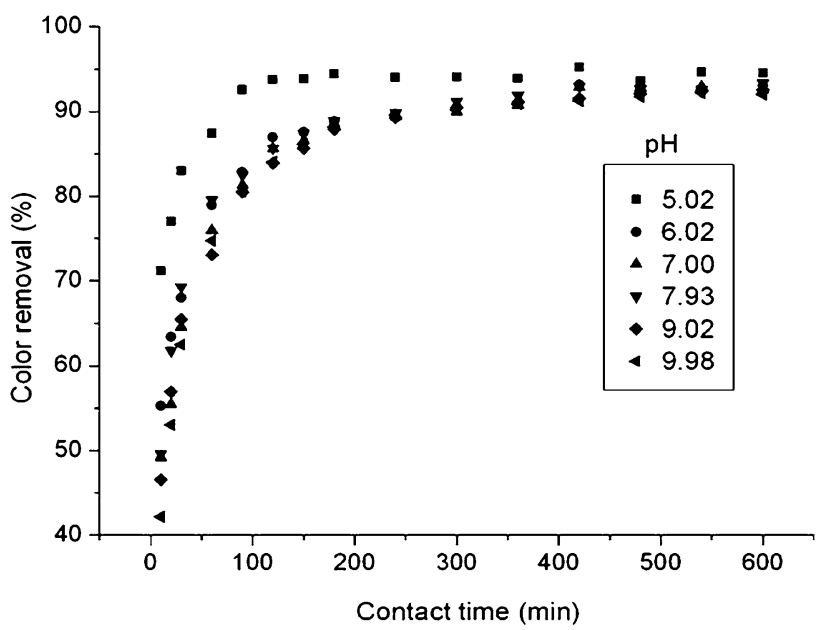

Fig. 6 Effect of $\mathrm{pH}$ on the percentage of colour removal of Congo Red (Lian et al. 2009) 
composite was reported by Abd El-Latif and co-workers. The thermal stability of the polymer-kaolin composite evaluated using thermogravimetric analysis (TGA) starting from $427{ }^{\circ} \mathrm{C}$ was attributed to the loss of interstitial water in the kaolin structure, and the weight loss was $11.363 \%$ in accordance with the known water ratio in kaolin. The morphology of the prepared composite revealed that the composite prepared from kaolin and PVA (polyvinyl alcohol) and alginate mixture had almost uniform porosity with pore diameter range of 36-75 $\mu \mathrm{m}$. The diameter of the composite beads ranged from 1.9 to $2.4 \mathrm{~mm}$ (Abd El-Latif et al. 2010). The beads produced from kaolin with mixed polymer (PVA and alginate) exhibited rubber-like elastic properties; PVA contributed strength and durability to the beads, whereas alginate improved the surface properties and reduced the tendency to agglomerate (Dave and Madamwar 2006).

The mechanical properties of the composite studied to determine its availability for column operations showed that the beads of the prepared composite have excellent mechanical strength under stirring for $72 \mathrm{~h}$ at $1000 \mathrm{rpm}$. The swelling behaviour of the beads revealed that the composite beads swelling in water increased with time till they reached equilibrium after $5 \mathrm{~h}$. The produced polymerkaolin composite was suitable to be used in column operation after being swollen in water for $5 \mathrm{~h}$ to avoid column clogging during the treatment process. However, it was observed that the alginate and PVA matrix had a small dye uptake due to the hydroxide groups that are suitable for cationic dye removal. On the other hand, the presence of the polymer matrix enhanced the percentage dye removal than the free kaolin, due to the presence of hydroxide groups associated with the polymer matrix. The percentage dye removal increased from $70.3 \%$ to $92.7 \%$ after $360 \mathrm{~min}$, upon using composite beads instead of free kaolin. The adsorption rate decreased through the first adsorption hour, due to the diffusion limitation of dyes to reach to the active adsorption sites (kaolin) through the composite beads (Abd El-Latif et al. 2010).

The amount of MB removed by organic-kaolin composite increased, reaching a maximum value with increase in contact time and almost became constant, after $360 \mathrm{~min}$ when equilibrium was attained. There was no significant increase in the percentage dye removal as the bead diameter increased from $0.5 \mathrm{~mm}$ to $2 \mathrm{~mm}$; despite the fact that composite beads had swelling characteristics, there were no variation on both the rate and the percentage of dye removed for the swollen beads and the dry ones due to the effect of the different operating variables in the batch process that eliminated the swelling effect. The removal of MB dye increased with increasing composite dosage. Increasing the adsorbent dosage at constant MB concentration provided more available adsorption sites for the dye and thus increased the extent of dye removal (Banat et al. 2003; Urses et al. 2006). However, the ratio of dye adsorbed to the composite $\left(\mathrm{mg} \mathrm{g}^{-1}\right)$ decreased with the increase in composite dosage from 3.37 to $1.53 \mathrm{mg} \mathrm{g}^{-1}$ (Abd El-Latif et al. 2010).

The removal of dye decreased from 100 to $61.6 \%$ on increasing the initial dye concentration from 10 to $500 \mathrm{mg} \mathrm{L}^{-1}$ after $360 \mathrm{~min}$; this was attributed to the increase of MB dye molecules adsorption onto the external surface of the organic-kaolin composite, which increased significantly the local dye concentration, giving rise to the formation of aggregates of the dye on the composite particles. However, the increase of initial dye concentration from 10 to $500 \mathrm{mg} \mathrm{L}^{-1}$ led to an increase in the adsorption capacity of the dye onto composite from 1 to $30.8 \mathrm{mg} \mathrm{g}^{-1}$. The effect of $\mathrm{pH}$ of the dye solution on the amount of dye adsorbed was studied by varying the initial $\mathrm{pH}$ under constant process parameters. The percentage removal of the MB solution after an adsorption period of $360 \mathrm{~min}$ was increased from 76 to $93.4 \%$ between $\mathrm{pH}$ values $2-12$. The removal capacity showed the same behaviour, as it increased from 1.52 to $1.87 \mathrm{mg} \mathrm{g}^{-1}$. The lower adsorption of MB at acidic $\mathrm{pH}$ was due to the presence of excess $\mathrm{H}^{+}$ ions that competed with the dye cation for adsorption sites. As the $\mathrm{pH}$ of the system increased $(\mathrm{pH}>8)$, the number of positively charged available sites decreased, while the number of the negatively charged sites increased. The negatively charged sites favoured the adsorption of $\mathrm{MB}$ dye cation due to electrostatic attraction. The final $\mathrm{pH}$ of the solution was found to decrease only slightly (by 0.5 $0.7 \mathrm{pH}$ units) after adsorption of $\mathrm{MB}$ (in cationic form) with the release of $\mathrm{H}^{+}$ions from the active site of the adsorbent surface (Abd El-Latif et al. 2010).

The effect of stirring speed (in rpm) on the percentage removal of dye at different concentrations showed that the percentage removal affected the agitation speed for values between 0 and $100 \mathrm{rpm}$, thus confirming that the influence of external diffusion on the sorption kinetic control played a significant role. In contrast, there were small effects of agitation in the range of $100-750 \mathrm{rpm}$; thus, while increasing the mixing rate from 750 to $1000 \mathrm{rpm}$, the percentage removal decreased from 93.3 to nearly $91.1 \%$. The decrease was attributed to an increased desorption tendency of dye molecules and/or having similar speed of organic-kaolin composite particles and adsorbate ions (i.e. the formation of a more stable film around the organickaolin composite particles). Increasing mixing speed to $750 \mathrm{rpm}$ caused deformation of the stable film, and disappearance of film diffusion control resulted from the organic-kaolin composite particles and adsorbate ions that move at the same speed (Abd El-Latif et al. 2009).

The adsorptive capacity of natural and burnt kaolinitic clay for removal of CR dye was reported by Nwokem and 
co-workers. The amount of $\mathrm{CR}$ adsorbed per unit mass of adsorbent at equilibrium increased as $\mathrm{pH}$ increased from 2 to 5 for both natural and burnt kaolinitic clay, reaching a maximum at $\mathrm{pH} 5$ with adsorption efficiency of $84 \%$ and $94 \%$ for natural and burnt kaolinitic clay, respectively. The amount of dye adsorbed per unit mass of adsorbent remained constant with increasing $\mathrm{pH}$ until $\mathrm{pH}$ 9; thereafter adsorption decreased with increase in $\mathrm{pH}$. Above $\mathrm{pH} 9$, the negative charge density on the surface of the adsorbent decreased leading to a gradual decline in the removal ability of the clay. However, the plateau observed between $\mathrm{pH}$ values 5 and 9 indicated that the presence of high concentrations of hydroxonium ions did not influence the kinetics of adsorption and, consequently, the removal was at its maximum. In addition, the acid-base dissociation of the hydroxylated oxides of the clay followed an ion exchange mechanism (Nwokem et al. 2012).

The removal efficiency increased from $28 \%$ to $51 \%$ within $10 \mathrm{~min}$ on increasing the adsorbent dosage from 0.25 to $1.0 \mathrm{~g}$ (for initial dye concentration $40 \mathrm{mg} \mathrm{L}^{-1}$, solution volume $50 \mathrm{~mL}$ and at $\mathrm{pH}=8$, at $25^{\circ} \mathrm{C}$ ). Similarly, at the conditions listed above, there was significant increase in removal efficiency as time was gradually increased to $60 \mathrm{~min}$ due to the fact that there were still active sites in each clay dosage; therefore, increase in contact time led to increased removal efficiency until the sites were saturated. The removal efficiency of the burnt clay was higher than that of the natural clay for each clay dosage investigated; thus, the burnt clay with a monolayer (maximum) adsorption capacity of $172.4148 \mathrm{mg} \mathrm{g}^{-1}$ has greater capacity for the uptake of the CR dye as compared to $45.8930 \mathrm{mg} \mathrm{g}^{-1}$ for the natural clay (Nwokem et al. 2012).

\section{Montmorillonite}

The batch adsorption technique for the removal of $\mathrm{MG}$ and FG dyes using montmorillonite clay as adsorbent showed maximum adsorption at $3 \times 10^{-4}$ and $6.3 \times 10^{-4} \mathrm{M}$ concentrations of MG and FG dyes, respectively. $1.0 \mathrm{~g}$ adsorbent system showed optimum adsorption over varied amounts of adsorbent of 0.1-1.2 g using dye concentration of $3 \times 10^{-5} \mathrm{M}$. Adsorptions of the dyes increased with increasing time and reached maximum removal at the adsorption equilibrium. Maximum adsorption capacities were obtained at 10 and 30 min for FG-montmorillonite and MG-montmorillonite clay systems respectively (Tahir et al. 2010).

The mean free energy of sorption for FG-montmorillonite clay system increased with the rise in temperature, indicating an increase in the dye sorption with the increase in temperature. Decrease in mean free energy of sorption with the increase in temperature for MG-montmorillonite clay system indicated less adsorption capacity at higher temperatures. The monolayer capacity for FG-montmorillonite system decreased with increase in temperature, indicating high affinity of FG at low temperatures, while MG-montmorillonite system monolayer capacity increased with increase in temperature. The values of $\Delta G^{\circ}$ for both systems were negative at different temperatures, which showed the spontaneous behaviour of the adsorption process (Table 3). Adsorption of both dyes on montmorillonite clay was exothermic in nature as reflected in the Langmuir adsorption isotherm and also corroborated by the positive $\Delta H^{\circ}$ values. The $\Delta S^{\circ}$ values showed random behaviour. The FG-montmorillonite and MG-montmorillonite systems showed about $97 \%$ dye removal at $313 \mathrm{~K}$ in the comparative removal studies carried out at different temperatures. The montmorillonite clay can be efficiently utilized as an adsorbent for the removal of toxic dyes from aqueous solutions according to surface morphology studies, which showed changes on the active sites of the adsorbent so much that the excess amounts of dye contents were adsorbed on the surface (Tahir et al. 2010).

The effects of adsorbent dose, initial $\mathrm{pH}$, dye concentrations and temperature on Basic Blue 16 (BB16) adsorption by montmorillonitic clay revealed that the adsorption rates of the dye were very fast at the initial

Table 3 Thermodynamic parameters for the adsorption of malachite green and Fast Green dyes on montmorillonite clay (Tahir et al. 2010)

\begin{tabular}{lcllllll}
\hline Dye & Concentration $\left(\mathrm{mol} \mathrm{L}^{-1}\right)$ & $\Delta H^{\circ}\left(\mathrm{kJ} \mathrm{mol}^{-1}\right)$ & $\Delta S^{\circ}\left(\mathrm{kJ} \mathrm{deg}^{-1} \mathrm{~mol}^{-1}\right)$ & \multicolumn{4}{l}{$\Delta G^{\circ}\left(\mathrm{kJ} \mathrm{mol}^{-1}\right)$} \\
\cline { 5 - 7 } & & & & $303 \mathrm{~K}$ & $308 \mathrm{~K}$ & $313 \mathrm{~K}$ & $318 \mathrm{~K}$ \\
\hline Malachite green & $0.7 \times 10^{-4}$ & 2.016 & 1.496 & -451.27 & -458.72 & -466.23 & -473.71 \\
& $9 \times 10^{-4}$ & 0.405 & 3.939 & -1193.10 & -1212.80 & -1232.50 & -1252.19 \\
& $1 \times 10^{-4}$ & 0.787 & 2.726 & -8285.19 & -838.82 & -852.41 & -866.08 \\
Fast green & $3 \times 10^{-4}$ & 2.641 & 3.003 & -907.26 & -922.28 & -937.29 & -952.31 \\
& $4.2 \times 10^{-4}$ & 0.422 & 1.951 & -590.73 & -600.48 & -610.24 & -619.98 \\
& $6.3 \times 10^{-4}$ & 0.304 & 2.376 & -719.62 & -731.50 & -743.38 & -755.26 \\
& $8.3 \times 10^{-4}$ & 0.198 & 2.684 & -813.05 & -826.47 & -839.84 & -853.31 \\
& $1.6 \times 10^{-3}$ & 0.142 & 2.816 & -853.10 & -867.18 & -881.26 & -895.34 \\
\hline
\end{tabular}


stages for all the four parameters tested, while it slowed gradually as the equilibrium was approached due to the reduction of available active sites on montmorillonitic clay. An inverse relationship was observed between BB16 removal and the adsorbent dosage. The amount of dye adsorbed onto montmorillonitic clay decreased with increase in adsorbent dose. The adsorption capacity of the adsorbent was maximum at $\mathrm{pH} 3.6$ and further increase in $\mathrm{pH}$ resulted in a negative effect on BB16 adsorption due to the changes in swelling properties and surface chemistry of clay with $\mathrm{pH}$ as corroborated by Gurses et al. 2006 (Gunay et al. 2013).

The initial dye concentration affected the adsorption capacity and the equilibrium time as the adsorption process reached equilibrium rapidly at low dye concentrations, but the equilibrium time was longer at higher concentration. The initial BB16 concentration enhanced the adsorption capacity of montmorillonitic clay due to increased gradient between the dye solution and adsorbent. A higher gradient (1000 $\mathrm{m} \mathrm{L} \mathrm{L}^{-1}$ ) promoted the driving force for the transfer of dye molecules from the solution to the adsorbent pore surfaces. The temperature also had profound effect on the removal of BB16 at higher dye concentrations, although adsorption capacities were close at all temperatures at $<500 \mathrm{mg} \mathrm{L}^{-1}$ initial BB16 concentration; this was attributed to increased penetration of dye molecules inside micropores of the adsorbent at higher temperatures (Gunay et al. 2013).

The spontaneous and feasible nature of BB16 adsorption by montmorillonitic clay was reflected in the negative $\Delta G^{\circ}$ values, as adsorption of BB16 was more favourable at higher temperatures and lower initial dye concentrations due to higher negative values of $\Delta G^{\circ}$. The dye molecules were removed from the liquid medium by physisorption. The positive values of $\Delta S^{\circ}$ implied an increase in the degree of dispersion of the adsorbed species. The positive values of $\Delta H^{\circ}$ suggested that adsorption was an endothermic process and that heat was consumed during the adsorption of BB16 by montmorillonitic clay, which was also supported by an increase of adsorption capacity with temperature (Gunay et al. 2013).

\section{Soil nanoclays}

The amount of $\mathrm{CV}$ and $\mathrm{MB}$ adsorbed on soil clays (size $<2000$ and $<100 \mathrm{~nm}$ ) in aqueous solution increased with the increase in reaction time. For all the soil clays, the rate of dye adsorption in soil clays which was rapid within the first $30 \mathrm{~min}$ of the $360 \mathrm{~min}$ reaction period (fast reaction) and relatively slow after $30 \mathrm{~min}$ (slow reaction) demonstrated that the dye adsorption consists of multiple rate processes (Fig. 7a). The amount of dye adsorbed followed the sequence of $\mathrm{MB} \quad(<100 \mathrm{~nm}$ soil clay,
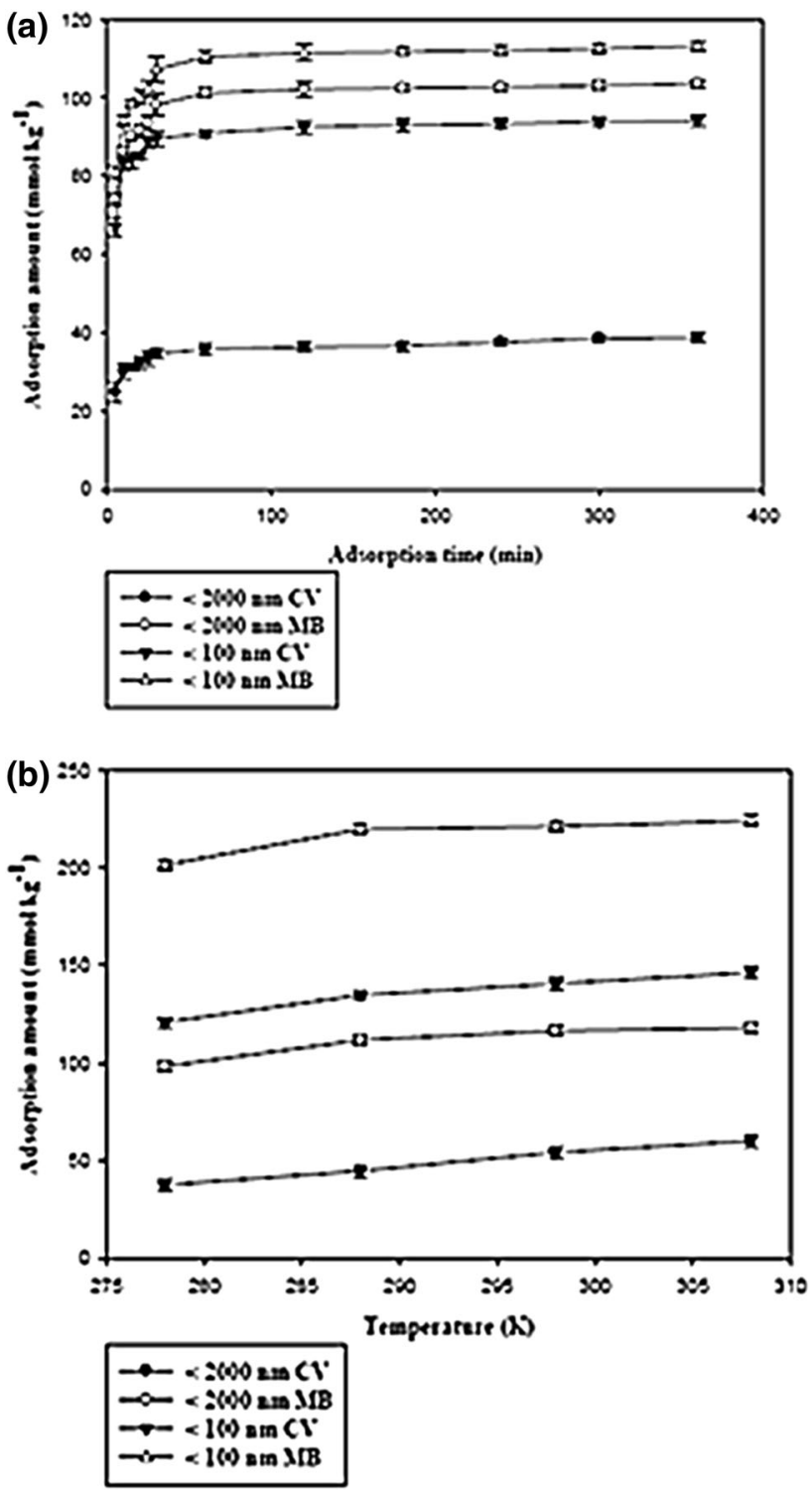

Fig. 7 a Equilibrium adsorption times of $\mathrm{CV}$ and $\mathrm{MB}$ dyes onto the clays (Chen et al. 2011). b Effect of temperature on the adsorption of MB and CV to the clays (Chen et al. 2011)

$\left.80.77-113.13 \mathrm{mmol} \mathrm{kg}^{-1}\right)>\mathrm{MB} \quad(<2000 \mathrm{~nm}$ soil clay, $\left.74.02-103.68 \mathrm{mmol} \mathrm{kg}^{-1}\right)>\mathrm{CV} \quad(<100 \mathrm{~nm}$ soil clay, $\left.67.13-94.14 \mathrm{mmol} \mathrm{kg}^{-1}\right)>\mathrm{CV} \quad(<2000 \mathrm{~nm}$ soil clay, 24.75-38.72 $\mathrm{mmol} \mathrm{kg}^{-1}$ ) (Chen et al. 2011).

The amounts of $\mathrm{CV}$ and $\mathrm{MB}$ dyes adsorbed on each adsorbent increased with the increase in temperature of adsorption, suggesting that temperature had a significant influence on the adsorption amount of the soil clay, viz $<2000 \mathrm{~nm}(\mathrm{CV}, 37.50-60.05$ and $\mathrm{MB}, 98.28-117.89$ $\left.\mathrm{mmol} \mathrm{kg}{ }^{-1}\right)$ and $<100 \mathrm{~nm}(\mathrm{CV}, 120.88-146.29$ and MB, 201.39-224.12 $\mathrm{mmol} \mathrm{kg}^{-1}$ ) (Fig. 7b). The adsorbed amount was enhanced by using clay of soil nanoparticle size, because the diffusion of CV and MB dye molecules in 
the aqueous phase became faster gradually with an increased temperature of adsorption, thus promoting the exchange interaction between the dye molecules and cations on the soil clay surface. Soil nanoclays have greater percentage of dye adsorbed compared with untreated soil clay minerals $(<2000 \mathrm{~nm})$ because of the increased surface area and greater pore volume. The maximum amount of $\mathrm{CV}$ and $\mathrm{MB}$ adsorbed on soil nanoclays are about two to three times higher than those of soil clays $(<2000 \mathrm{~nm})$ (Chen et al. 2011).

\section{Ghassoul}

Elass's group observed that the $\mathrm{pH}$ affected the adsorption capacities very slightly in the removal of MB from aqueous solution using ghassoul over a $\mathrm{pH}$ range of $3-11$, so no initial $\mathrm{pH}$ adjustment on the dye solutions was made for subsequent studies because the $\mathrm{pH}$ of freshly prepared dye solution was about 4.5-5. Temperature change had almost no effect on the adsorption capacity of MB as reflected in the adsorption isotherms at different temperatures. The equilibrium adsorption of MB increased with increase in initial dye concentration, thus showing how the adsorption process depended on the initial concentration. A strong affinity of the dye molecules for the surface sites on ghassoul was indicated by the initial steeply rising part (first $30 \mathrm{~min}$ ) of the adsorption isotherms. The extent of adsorption reached a limiting value around $300 \mathrm{mg} \mathrm{g}^{-1}$ (Elass et al. 2010).

The MB adsorption increased with increase in contact time when the initial concentration of the MB solution was varied from 100 to $600 \mathrm{mg} \mathrm{L}^{-1}$ (Fig. 8). The high affinity between the adsorbent and the adsorbate was indicated by the fast adsorption process with about 90-99 \% MB molecules adsorbed on ghassoul within the first 10-20 min. However, the amount of dye adsorbed reached equilibrium in $90 \mathrm{~min}$. Pseudo-second-order equation provided the best correlation for the experimental data, indicating that chemisorption was the adsorption process. Ghassoul was an excellent adsorbent for MB removal at a fast pace, indicating that the adsorption was a surface phenomenon and that the surfaces were readily accessible to the ions in solution (Elass et al. 2010).

\section{Open burnt clay}

The effect of contact time, initial dye concentrations of $40-80 \mathrm{mg} \mathrm{L}^{-1}$ and initial $\mathrm{pH}$ of 3 of $\mathrm{CR}$ from aqueous solution using open burnt clay as an adsorbent showed that the dye removal was rapid in the initial stage of contact time and gradually decreased with time until equilibrium was reached in approximately $200 \mathrm{~min}$ during a $500 \mathrm{~min}$ reaction time (Fig. 9). The rapid removal of dye molecules

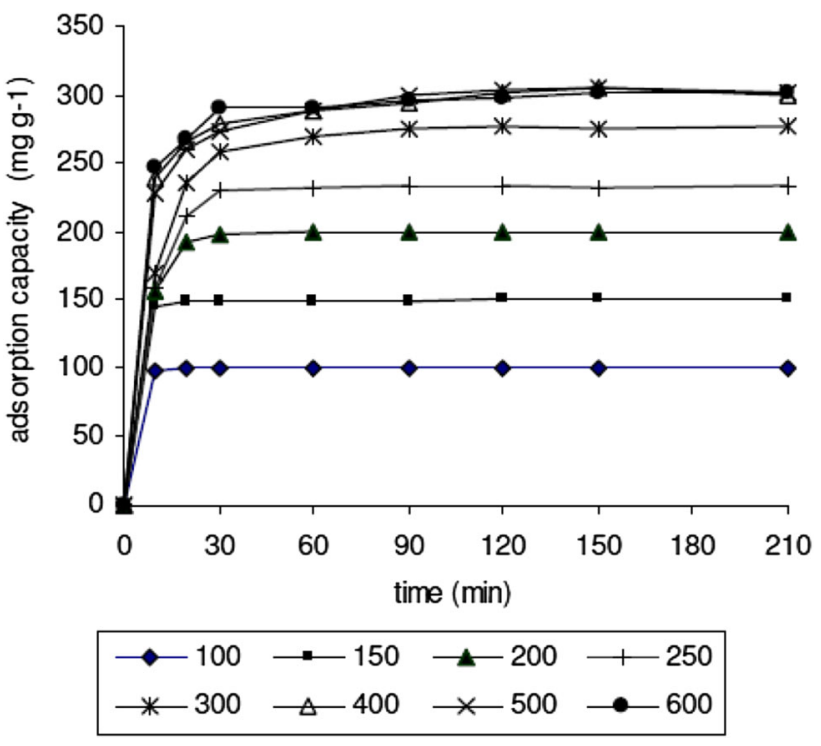

Fig. 8 Effect of initial concentration $\left(\mathrm{mg} \mathrm{L}^{-1}\right)$ on the adsorption of MB onto ghassoul (Elass et al. 2010)

in the initial stages of contact time and gradual decrease until equilibrium suggested the formation of monolayer coverage of dye molecules on the outer surface of the adsorbent and pore diffusion onto the inner surface of the adsorbent particles through the film due to continuous agitation maintained during the experiments (Mumin et al. 2007).

Increasing $\mathrm{pH}$ of dye solution from 2 to 12 led to a decreased percentage dye removal from $94 \%$ to $2 \%$ due to aqua-complex formation and subsequent acid-base dissociation at the solid-solution interface, since the dye removal percentage was higher in acidic media. The increasing adsorbent dose of open burnt clay from 0.5 to $3 \mathrm{~g}$ (for initial dye concentration $50 \mathrm{mg} \mathrm{L}^{-1}$, solution volume $200 \mathrm{~mL}$ and at a $\mathrm{pH}=3$ ) resulted in increased removal efficiency of the $\mathrm{CR}$ adsorbed. The number of available adsorption sites increased with increase in adsorbent dose, leading to increase in removal efficiency due to the aggregation/agglomeration of adsorbent particles at higher concentration; thus a decrease in the total surface area of soil particles available for CR adsorption and an increase in diffusional path length were observed (Al-Degs et al. 2000). Particle interaction as a result of high sorbate concentration may also desorb some of the adsorbate which is only loosely and reversibly bonded to the surface. The percentage removal of CR by open burnt clay (94\%) showed comparable results with that of activated charcoal (almost $100 \%$ ). However, the high cost, disposal and regeneration problems of activated charcoal made the potentiality of open burnt clay for the effective removal of $\mathrm{CR}$ from aqueous solution a very promising alternative. The adsorption capacity of the regenerated burnt clay 

Congo Red onto open burnt clay (Mumin et al. 2007)
Fig. 9 Adsorption kinetics of

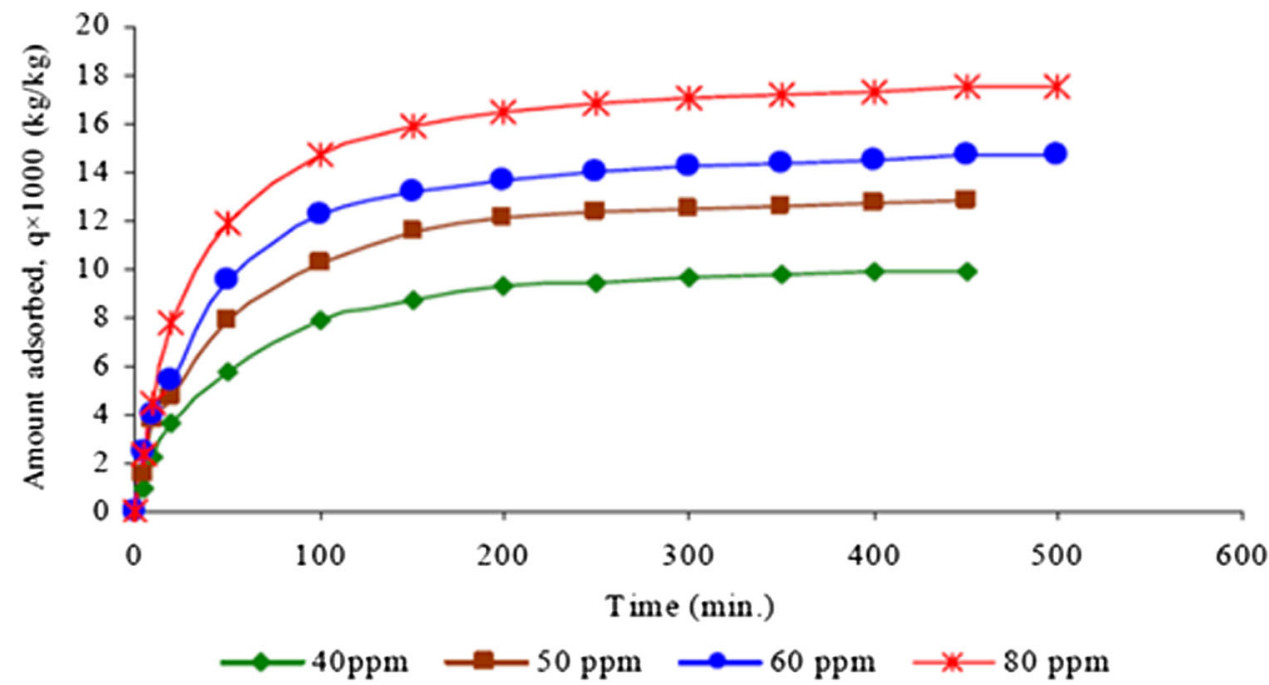

showed $98 \%$ recovery of the adsorption efficiency of the initial virgin adsorbent which decreased by only $1.1 \%$ (Mumin et al. 2007).

\section{Moroccan clay}

The adsorption of MG dye onto raw Moroccan clay in batch and dynamic system showed that the adsorption efficiency increased as the amount of clay increased due to the increased surface area, with an optimum clay dosage of $40 \mathrm{mg}$ (of clay) per $100 \mathrm{~mL}$. Equilibrium for the MG-raw clay system was reached at approximately $25 \mathrm{~min}$ of agitation. Increase in initial dye concentration resulted in an increased adsorption capacity, suggesting that the initial dye concentration played an important role in the adsorption capacity of the dye. Decreased breakthrough and exhaustion time at higher initial concentration may be due to the rapid exhaustion of the sorption sites; thus, the diffusion process was concentration dependent. The dye concentration increased with increasing dye loading rate and driving force for the mass transfer decreased in the adsorption zone length, leading to a net effect of appreciable increase in adsorption capacity (Bennani-Karim et al. 2011).

The breakthrough point decreased with decrease in bed height, and increase in bed height increased the breakthrough time; thus for the same influent MG concentration and fixed bed conditions, increased bed height resulted in longer distance for the mass transfer zone to reach the exit and therefore an increase in the breakthrough time. Also, the saturation of the bed was faster at higher MG concentration (Fig. 10). Higher MG uptake was observed at higher bed heights due to the increased specific surface of the crude clay which provided more fixation binding sites for the dye to adsorb. The increased adsorbent mass in a

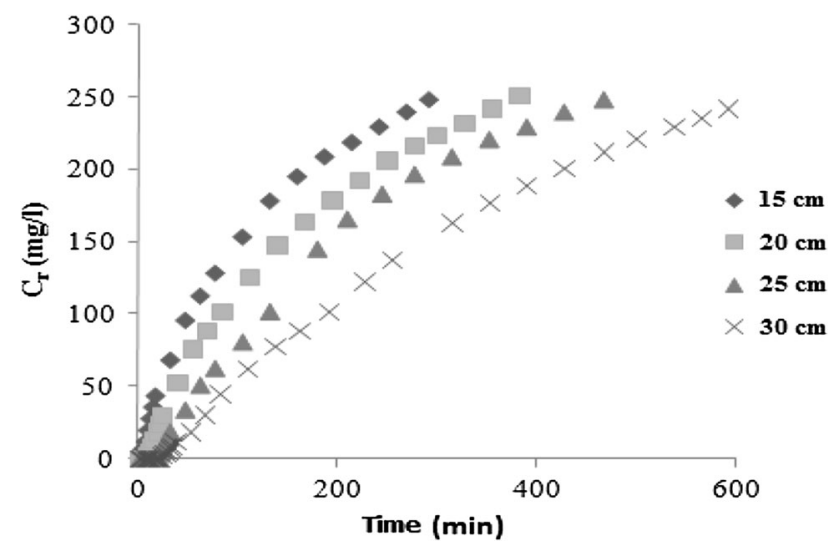

Fig. 10 Breakthrough curves for $M G$ adsorption on crude clay at different bed heights (initial dye concentration $=260 \mathrm{mg} \mathrm{L}^{-1}$, flow rate $=4 \mathrm{~mL} \mathrm{~min}^{-1}, \quad$ temperature $\left.=25 \pm 1{ }^{\circ} \mathrm{C}\right) \quad($ Bennani-Karim et al. 2011)

higher bed provided greater service area, which led to increased volume of the solution treated. The possibility of using fixed bed of mixed sand-clay in the separation of dyes from water revealed that the continuous adsorption system represented by the breakthrough curve was dependent on the initial dye concentration and adsorbent bed height as Moroccan clay showed an interesting capacity of separating MG from water (Bennani-Karim et al. 2011).

The removal of basic red 46 (BR46) dye from aqueous solution by adsorption onto Moroccan clay investigated by Bennani-Karim's group revealed that adsorption reached $95 \%$ of the total capacity in $20 \mathrm{~min}$. The uptake of the dye increased by the amount of clay added, and the maximum dye removal was achieved with $40 \mathrm{mg}$. The number of adsorption sites increased as the adsorbent mass increased, due to the increase in the adsorbent surface area and availability of more adsorption sites. However, further 
increase in the amount of the adsorbent did not affect the uptake capacity significantly. Also, increase in initial dye concentration led to an increase in the adsorption capacity, indicating that initial dye concentration played an important role in the adsorption capacity of the dye. Moreover, the initial rate of adsorption was greater for higher initial dye concentration, because the resistance to the dye uptake decreased as the mass transfer driving force increased. The $\mathrm{pH}_{\mathrm{pzc}}$ ( $\mathrm{pH}$ at point of zero charge) for the crude clay was 9.5 and the adsorption capacity of BR46 onto increased significantly from $\mathrm{pH} 9.5$ to 12 , indicating that the charge sign on the surface of the clay remained negative in a wide $\mathrm{pH}$ range (9.5-12), i.e. in basic solution, the negatively charged clay surface favoured BR46 adsorption. Therefore, the amount of BR46 adsorbed on the clay decreased with the decrease in $\mathrm{pH}$, attributed to the electrostatic repulsion between the positively charged surface and the positively charged dye molecules at $\mathrm{pH}$ below 9.5. Also, the lower adsorption of BR46 at acidic pH may be due to the presence of excess $\mathrm{H}^{+}$ions competing with dye cations for the adsorption sites (Bennani-Karim, et al. 2009).

The negative values of $\Delta G_{\text {ads }}$ showed that the adsorption of basic red 46 (BR46) onto clay was spontaneous, indicating that the process was exothermic in nature. The positive value of $\Delta S_{\text {ads }}$ showed increased randomness at the solid-solution interface during the adsorption of dye onto clay. The $\Delta G_{\text {ads }}$ value of $<-4.7 \mathrm{kcal} \mathrm{mol}^{-1}$ suggested that the process was controlled by physisorption (BennaniKarim et al. 2009).

\section{Red mud}

Red mud has been used for the removal of different dyes from water and wastewater. Table 4 reveals the adsorption capacity of raw and activated red mud (ARM) for the removal of different dyes in water. Gupta and his group utilized red mud for the removal of Rhodamine B, FG and MB dyes from wastewater. The percentage removal of Rhodamine B, FG and MB with red mud was 92.5, 94.0 and 75.0, while the optimum $\mathrm{pH}$ values for their removal were 1.0, 7.0 and 8.0, respectively. Decrease in the adsorption of these dyes in the presence of different concentrations of cationic and anionic surfactants, cetyltrimethylammonium bromide (CTAB) and manoxol 1B, was observed. The removal of about $95-97 \%$ of Rhodamine B, FG and MB was achieved at a flow rate of $0.5 \mathrm{~mL} \mathrm{~min}^{-1}$, but the removal decreased with increase in flow rate during column operations. The column capacity was higher than the adsorption capacity of batch experiments, due to a large concentration gradient which was continuously present at the interface zones as the dyecontaining sample passed through the column. However, the concentration gradient decreased with time in batch experiments. Desorption of Rhodamine B, FG and MB with some eluents (methanol, ethanol, acetone, sodium hydroxide, sulphuric acid, hydrochloric acid, nitric acid, etc.) showed that the desorption of dyes occurred easily with acetone (Bhatnagar et al. 2011; Gupta et al. 2004).

Waste red mud recycled for the adsorption of CR from aqueous solution showed an adsorption capacity of $4.05 \mathrm{mg} \mathrm{g}^{-1}$. Adsorption was found to be nearly quantitative at $\mathrm{pH}$ 2.0. The effect of $\mathrm{pH}$ and desorption studies suggested that mainly ion exchange was the mechanism of adsorption (Bhatnagar et al. 2011; Namasivayam and Arasi 1997). The ability of waste red mud to remove Procion orange dye at different initial dye concentrations, agitation time, adsorbent dosage and $\mathrm{pH}$ revealed that the percent removal decreased from 82 to 0 on increasing the initial $\mathrm{pH}$ of the solution from 2.0 to 11.0 , due to the aqua-complex formation and subsequent acid-base dissociation at the solid-solution interface (Namasivayam et al. 2002). However, desorption studies showed that maximum desorption occurred at a pH of 11 (Bhatnagar et al. 2011; Namasivayam et al. 2002). The Langmuir adsorption capacity of red mud used for the removal of Acid Violet dye from wastewater was $1.37 \mathrm{mg} \mathrm{g}^{-1}$. Quantitative dye removal occurred at $\mathrm{pH} 4.1$ and the desorption studies showed that ion exchange was the main mechanism involved in the sorption process (Bhatnagar et al. 2011; Namasivayam et al. 2001).

Batch adsorption experiments for the removal of CR dye from water using $\mathrm{HCl} \mathrm{ARM}$ revealed that the $\mathrm{pH}$ of the dye solution strongly affected the chemistry of both the dye molecules and the ARM in aqueous solution with effective

Table 4 Adsorption capacity of red mud for the removal of different dyes from water (Bhatnagar et al. 2011)

\begin{tabular}{llll}
\hline Adsorbent & Adsorbate & Amount adsorbed & Reference \\
\hline Red mud & Rhodamine B & $(1.01-1.16) \times 10^{-5} \mathrm{~mol} \mathrm{~g}^{-1}$ & Gupta et al. (2004) \\
Red mud & Fast Green & $(7.25-9.35) \times 10^{-6} \mathrm{~mol} \mathrm{~g}^{-1}$ & Gupta et al. (2004) \\
Red mud & Methylene Blue & $(4.35-5.23) \times 10^{-5} \mathrm{~mol} \mathrm{~g}^{-1}$ & Gupta et al. (2004) \\
Red mud & Congo Red & $4.05 \mathrm{mg} \mathrm{g}^{-1}$ & Namasivayam and Arasi (1997) \\
Red mud & Acid Violet & $1.37 \mathrm{mg} \mathrm{g}^{-1}$ & Namasivayam et al. (2001) \\
Acid-activated red mud & Congo Red & $7.08 \mathrm{mg} \mathrm{g}^{-1}$ & Tor and Cengeloglu (2006) \\
\hline
\end{tabular}


pH of 7.0 for adsorption (Tor and Cengeloglu 2006). Equilibrium was achieved in $90 \mathrm{~min}$ and the maximum monolayer sorption capacity for the adsorption of CR by ARM was $7.08 \mathrm{mg} \mathrm{g}^{-1}$ (Bhatnagar et al. 2011; Tor and Cengeloglu 2006). Fly ash and red mud have been employed as adsorbents for the removal of $\mathrm{MB}$ dye from aqueous solution. Heat treatment $\left(800{ }^{\circ} \mathrm{C}\right.$ for overnight) and chemical treatment $\left(1 \mathrm{~N} \mathrm{HNO}_{3}\right.$ solution for $24 \mathrm{~h}$ ) have also been applied to the as-received fly ash and red mud samples (Wang et al. 2005). Heat treatment reduced the adsorption capacity for both fly ash and red mud, but acid treatment by $\mathrm{HNO}_{3}$ induced a different effect on fly ash and red mud, which resulted in increased adsorption capacity of fly ash and decreased adsorption capacity of red mud. Lower adsorption capacity of heat-treated red mud was due to the decomposition of some organics and hydroxyl groups at high temperature, which were the main effective sites for adsorption. On the other hand, acid treatment dissolved the minerals in carbon and thus increased the pore volume and surface area of the fly ash sample, leading to increased adsorption. However, acid treatment for red mud neutralized the hydroxide ions on the basic surface, thus favouring adsorption of the basic dye (Bhatnagar et al. 2011; Wang et al. 2005).

\section{Raw clay}

Surface properties and adsorption mechanism of anionic Reactive Red 120 (RR120) dye onto raw clay was investigated by Errais' group. The kinetics of the RR120 adsorption on the four clays [Fouchana clay, smectite (SWy-1), kaolinite (KGa-2) and illite (IMt-2)] determined in the same operating conditions showed rapid dye removal in the initial stages of contact time and reached equilibrium after $20 \mathrm{~min}$ for Fouchana and $\mathrm{KGa}-2$, and after $60 \mathrm{~min}$ for SWy-1 and IMt-2 during a 180 min reaction time. The rapid adsorption during the first 20 min for $\mathrm{KGa}-2$ and Fouchana clay was due to the abundant availability of active sites on the clay surface; but with the gradual occupancy of these sites, the adsorption became less efficient. By contrast, adsorption of the RR120 dye on SWy-1 and IMt-2 was less rapid and completed in about $1 \mathrm{~h}$, indicating that for the same initial mass of clay and dye concentration, the adsorption rate was higher for $\mathrm{KGa}-2$ and Fouchana clay $(\sim 98 \%)$ than for SWy-1 $(\sim 4 \%)$ and IMt-2 $(\sim 3 \%)$ (Errais 2011). At the chosen experimental conditions, KGa-2, with the lowest CEC, possessed the highest adsorption rate and yield. The adsorption capacity of SWy-1 was low compared with that of KGa-2 or Fouchana clay (which contains $30 \%$ kaolinite), although it has high exchange capacity. Thus, the exchange phenomena between the layers were not the main processes of adsorption that was to be expected considering the negative surface charge of the clay and the anionic nature of the dye molecules; they may, however, be responsible for retention of dye molecules in the case of SWy-1 (Errais et al. 2012).

All $\Delta H_{\text {ads }}$ values for the four clays were negative, indicating that the process was exothermic in nature. The negative values of $\Delta G_{\text {ads }}$ for Fouchana clay and KGa-2 showed the spontaneous adsorption of RR 120 dye on these adsorbents, while the positive $\Delta G_{\text {ads }}$ values for SWy-1 and IMt-2 clays showed that the adsorption process was not spontaneous. Moreover, $\Delta G_{\text {ads }}$ values increased with temperature increase, indicating that the adsorption process on Fouchana and $\mathrm{KGa}-2$ was thermodynamically feasible at room temperature, but less at higher temperatures suggesting that adsorption occurred through electrostatic processes. The difference in adsorption capacity of the clays might thus be related to the surface characteristics and chemical nature. The potentiometric titration (Fig. 11) of RR120 in aqueous solution showed that four predominant species co-existed between the $\mathrm{pH}$ values 2 and 12, namely two phenolic $\mathrm{OH}$ groups adjacent to azo groups $\left(\mathrm{p} K_{\mathrm{a}}=11.54\right.$ and 9.38) and two de-protonated diaminochlorotriazine groups $\left(\mathrm{p} K_{\mathrm{a}}=4.4\right.$ and $\left.\ll 2\right)$ (Laera et al. 2011). The sulphonic acid groups were under anionic form at pH 2 (Jhimli et al. 2010), indicating that the RR120 dye was still in anionic form with six negatives sites under acidic $\mathrm{pH}(<4)$, but also with two positive sites. At $\mathrm{pH}<4$, the different measurements showed that (i) the charge of the dye was negative, but with positive charges at the chlorotriazine groups and (ii) the studied clay minerals were protonated at the sheet edges with the presence of positive charges; so at these low $\mathrm{pH}$ conditions, there was a combined effect on both the protonated clay surface and anionic dye molecules which favoured the adsorption of the dye. However, the solution $\mathrm{pH}$ was always higher than 4, but slightly acidic (5-5.7) for experiments with Fouchana and KGa-2 and basic (9-9.3) for the experiments with SWy-1 and IMt-2. This means that protonation of Fouchana and KGa-2 particle edges contributed only partly to the adsorption of the dye, whereas the basic $\mathrm{pH}$ conditions of SWy-1 and IMt-2 did not allow major dye adsorption on the clay edges (Errais et al. 2012).

The specific surface values of the studied clays decreased after adsorption, indicating that the surface access to adsorption decreased. Observations by electron microscopy showed particle aggregates covered by a compact film and a porosity that was no longer visible, especially in the Fouchana clay and SWy-1. In this the dye molecules completely filled the spaces between aggregates, thereby reducing the specific surface area. However, there was a coating of particles without complete filling of porosity in $\mathrm{KGa}-2$, which would have induced an increase in particle size, thus decreasing the surface/volume ratio and surface area (Velde 1995). However, the increase in 
the volume of small size pores $(<5 \mathrm{~nm})$ of Fouchana clay after adsorption and decrease in the volume of larger pores (5-14 $\mathrm{nm})$ suggested a more extensive filling by dye in larger pores contrary to small pores and thus an increase in the number and volume of small pores. There was a decrease in volume in both pore sizes in KGa-2, suggesting that dye adsorption occurred more uniformly in small as well as larger pores, which is consistent with electron microscopy observations (Errais et al. 2012).

CEC values before adsorption were very low for $\mathrm{KGa}-2$ compared to those of SWy-1 and Fouchana clay. Unlike specific surface values, the CEC values increased significantly after adsorption of the dye, especially for KGa- 2 indicating that there was creation of additional negatively charged sites, which could adsorb cations (i.e. the multiple sulphonate groups of the dye molecules). All of the sulphonate groups did not interact with the clay; thus the remaining free groups provided additional adsorption sites for positively charged ions. The amount of exchangeable aluminium in Fouchana and KGa-2 clays was higher compared to Swy-1, both before and after dye adsorption because the presence of exchangeable aluminium was a factor favouring the adsorption of organic anions (Yariv 2002). The metal cations adsorbed on edge sites contributed to the positive net surface charge and formed bridges between the clay particles and organic anions due to the effectiveness of anionic dye adsorption by kaolinite and Fouchana clay (Errais et al. 2012).
All the clay suspensions were stable at zeta potential values below -25 except for IMt-2. The high zeta potential absolute values and the low $\mathrm{pH}$ of Fouchana clay and KGa2 indicated a good particle dispersion and front edge aggregation type where porosity was open and accessible to anionic dyes (Tombàcz and Szekeres 2006; Zbik et al. 2008; Mietta et al. 2009). The high zeta potential absolute value and basic $\mathrm{pH}$ of $\mathrm{SWy}-1$ contributed to dispersion of particles and less dense aggregation (Lagaly and Ziesmer 2003). After adsorption of dye and suspension in distilled water, zeta potential decreased (in absolute value) indicating a tendency towards flocculation. There was still compression of the double layer and charge neutralization of the surface by counterions, inducing a decrease in zeta potential (Table 5) due to counterions being adsorbed on the basal surfaces of clay particles or between dye molecules and the adsorbed and closely packed dye molecules preventing the counterions from diffusing in the aqueous solution. The smectite in Fouchana clay played a lesser role in dye adsorption where the main process was related to the presence of exchangeable calcium and dissociated $\mathrm{Al}-\mathrm{OH}$ groups at crystal edges. The role of illite is unimportant compared with that of kaolinite or smectite. Natural untreated clay, as far as it contains a major amount of kaolinite, is an effective material in the adsorption of anionic dye molecules at ambient temperature and with initial $\mathrm{pH}$ of the dye solution slightly acidic (Errais et al. 2012).
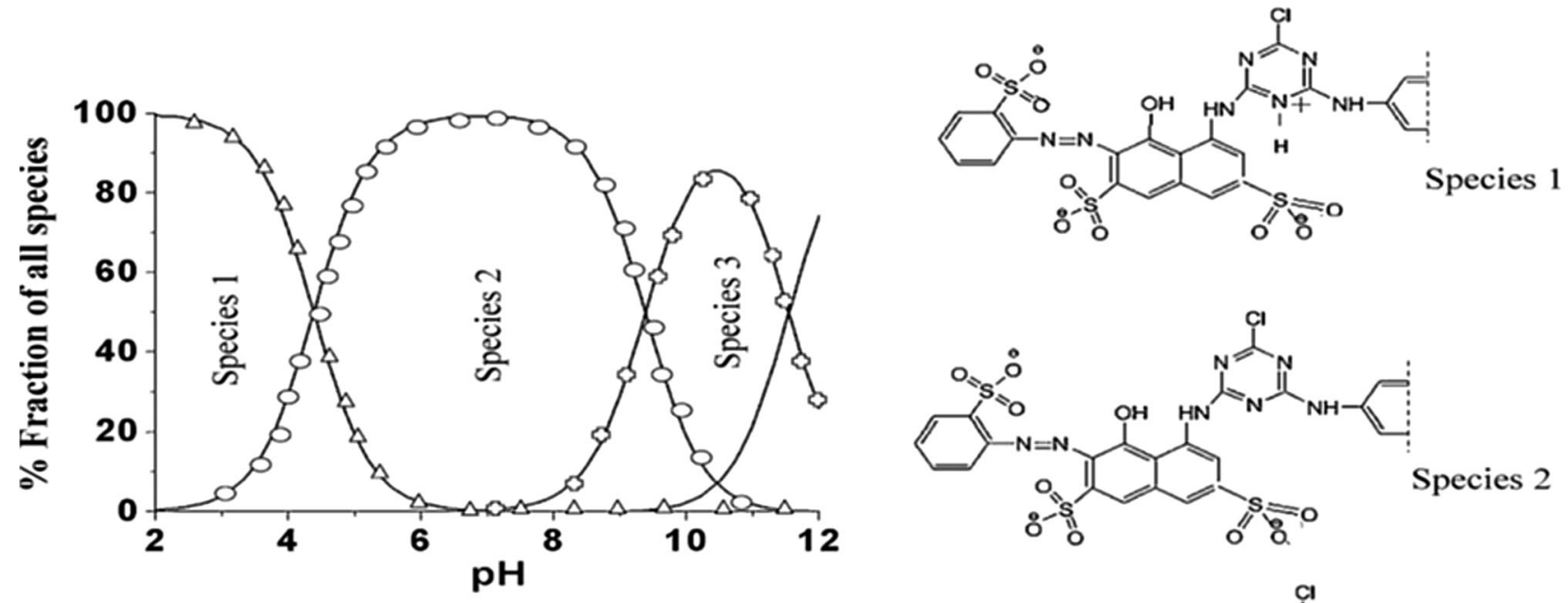

$$
\begin{aligned}
& \Delta \\
& \begin{array}{l}
\text { \% Fraction species } 1 \\
\text { \% Fraction species } 2
\end{array} \\
& \%
\end{aligned}
$$
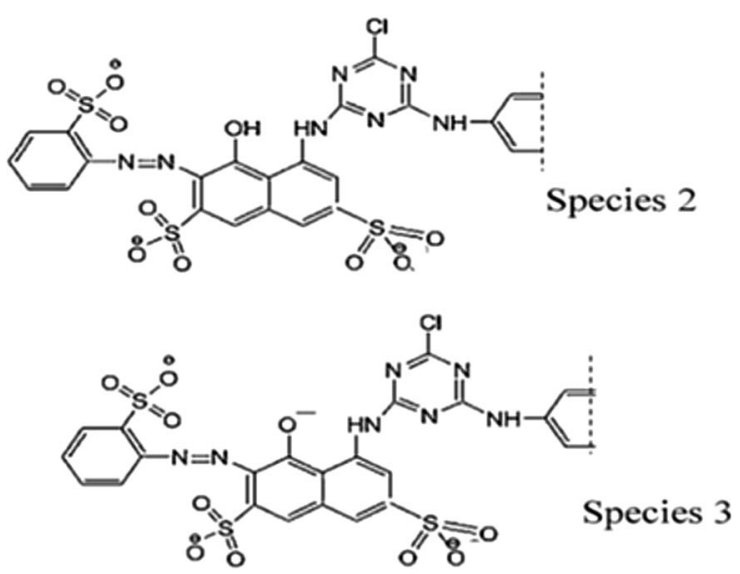

Fig. 11 Potentiometric titration of RR120 dye aqueous solution and speciation between pH 2 and 12 (half molecule species are represented) (Errais et al. 2012) 
Table 5 Zeta potential of Fouchana clay, smectite SWy-1, kaolinite KGa-2 and illite IMt-2 before and after adsorption (Errais et al. 2012)

\begin{tabular}{|c|c|c|c|c|}
\hline & \multicolumn{2}{|l|}{$\xi(\mathrm{mv})$} & \multicolumn{2}{|l|}{$\mathrm{pH}$} \\
\hline & Before adsorption & After adsorption & Before adsorption & After adsorption \\
\hline Fouchana clay & -38 & -31.6 & 5 & 5.7 \\
\hline Kaolinite KGa-2 & -29.5 & -26.8 & 5.4 & 5 \\
\hline Smectite Swy-1 & -34.5 & -32 & 9.3 & 9.2 \\
\hline Illite IMt-2 & -5.8 & -16 & 9.3 & 9 \\
\hline
\end{tabular}

\section{Activated clay}

Hsu and co-workers investigated the adsorption behaviour of basic dyes [basic red 18 (BR 18); basic red 46 (BR 46); basic yellow 28 (BY 28)] on activated clay. The adsorption rate was about the same regardless of changes in agitation speed above $200 \mathrm{rpm}$, which was consistent with a previously reported result (Wu et al. 1994) implying that the transfer of solute on the particle surface was not affected by film thickness. However, pore diffusion turned out to be a major limiting factor, as liquid film diffusion on the external particle surface was caused mainly by the electrostatic attractive forces between the negatively charged activated clay and the positively charged basic dye molecules. Only a very small amount of clay was present in the $1 \mathrm{~g} \mathrm{~L}^{-1}$ experiment, indicating random adsorption due to the adsorption site on the activated clay adsorbing the BR 18 molecules. However, the adsorbability diminished as the amount of clay increased, i.e. the amount of dyes adsorbed per unit mass of clay decreased with an increasing amount of clay. The adsorbent surface area was highly dependent on the particle size, which in turn affected the adsorption rate as well as the adsorption capability. The specific surface areas were $147.33,99.51,89.87$ and $87.68 \mathrm{~m}^{2} \mathrm{~g}^{-1}$ for particle sizes of $<38,38-63,63-75$ and $75-106 \mathrm{pm}$, respectively, among which the group with size $<38 \mathrm{pm}$ showed the best result for BR 18. Similar results were also observed for BR 46 and BY 28. The larger the specific surface area, the greater is the adsorption capacity and the rapid is the adsorption rate. The higher the initial dye concentrations, the higher is the adsorbate per unit adsorbent mass. Similar results were also observed for BR 46 and BY 28. At low initial concentration (e.g. less than $110.56 \mathrm{mg} \mathrm{L}^{-1}$ ), instantaneous adsorption occurred without significant lag time (Fig. 12) (Hsu et al. 1997). A summary of adsorption capacities of some clay adsorbents for the removal of different dyes from water are presented in Table 6.

The presence of $\mathrm{NaCl}$ (an electrolyte) greatly enhanced the adsorption capability of activated clay as the charge density in the diffusion layer was significantly increased, which in turn minimized the volume of diffusion layer required to neutralize the surface charge. Sodium cation had a thinning effect on the diffusion layer formed on the

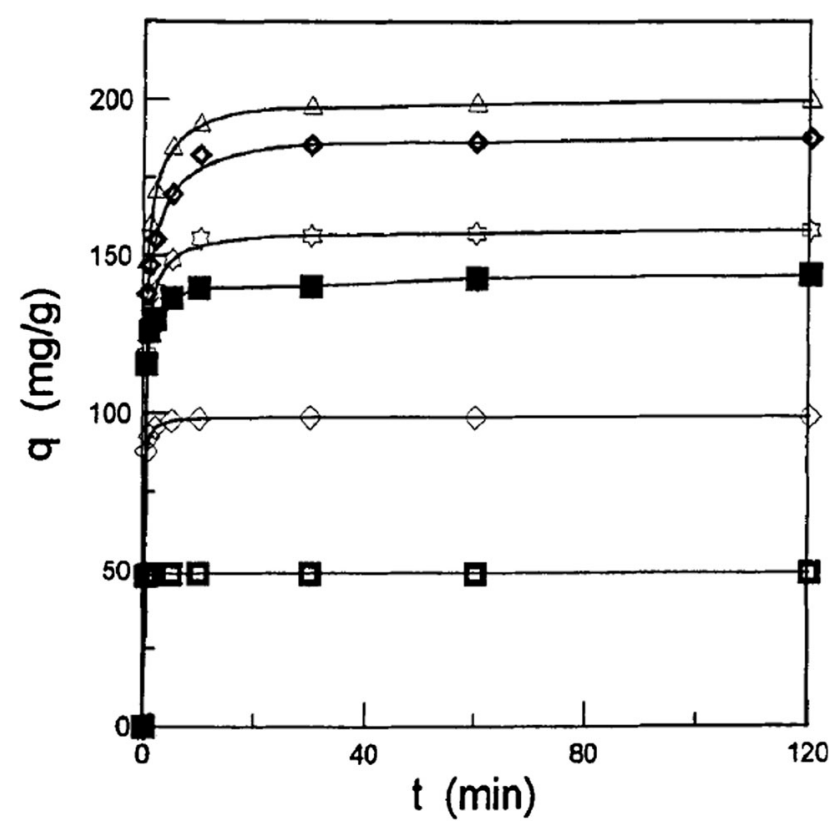

Fig. 12 Effect of initial concentration of dyes on adsorption capacity for BR18. Temperature $=30^{\circ} \mathrm{C} . \quad \mathrm{rpm}=500, \mathrm{pH} 3,0<d_{\mathrm{p}}$ $\leq 38 \mu \mathrm{m}$, activated clay $=2 \mathrm{~g} \mathrm{~L}^{-1}$, open square $C_{\mathrm{o}}=110.56$ $\mathrm{mg} \mathrm{L}^{-1}, \diamond C_{\mathrm{o}}=213.53 \mathrm{mg} \mathrm{L}^{-1}$, filled square $C_{\mathrm{o}}=326.16 \mathrm{mg} \mathrm{L}^{-1}$, open star $C_{\mathrm{o}}=366.76 \mathrm{mg} \mathrm{L}^{-1}$, open diamond $C_{\mathrm{o}}=443.29$ $\mathrm{mg} \mathrm{L}^{-1}$, open triangle $C_{\mathrm{o}}=519.83 \mathrm{mg} \mathrm{L}^{-1}$ (Hsu et al. 1997)

surface of the particles. Although the total net charge did not change, the thickness of the diffusion layer diminished significantly (Benefield et al. 1982). Similar results with little discrepancies were obtained for BR 18 and BY 28 due to the differences in the molecular structures of the dyes. The wastewater temperature affected the adsorption rate as well as the adsorption capacity; in some positively and in others negatively. However, lower temperatures facilitated the adsorption of BR 46 with similar results observed for BY 28 and BR 18, although they were not as significant as for BR 46. The activated clay showed excellent affinity for the basic dyes and the degree of adsorbability depended greatly on the species of basic dyes, temperature and relative concentrations of the adsorbate and the adsorbent. Sodium chloride contained in the wastewater exerted a positive effect on the adsorption (Hsu et al. 1997). 
Table 6 Summary of adsorption capacities of some clay adsorbents for the removal of different dyes from water as discussed in this review

\begin{tabular}{|c|c|c|c|c|}
\hline Clay adsorbent & Adsorbate & $\%$ removal & $\begin{array}{l}\text { Optimum conditions: } \\
\text { pH; contact time (min) }\end{array}$ & References \\
\hline Bentonite & Malachite Green & $>90$ & $9 ; 10$ & Tahir and Naseem (2006) \\
\hline Iraqi bentonite modified clay & Fast Green & 97 & $<7 ; 30$ & Ehssan et al. (2011) \\
\hline Iraqi bentonite modified clay & Crystal Violet & 90 & $>7 ; 30$ & Ehssan et al. (2011) \\
\hline Acid-activated Algerian bentonite & Methylene Blue & 91.65 & $10 ; 5$ & Bellir et al. (2010) \\
\hline Natural bentonite, modified by thermal activation & Diazo Dye & 91.62 & $<10 ; 120$ & Toor and Jin (2012) \\
\hline Natural bentonite, modified acid activation & Diazo Dye & 92.75 & $<10 ; 120$ & Toor and Jin (2012) \\
\hline $\begin{array}{l}\text { Natural bentonite, modified by combined } \\
\text { acid and thermal activation }\end{array}$ & Diazo Dye & 96.65 & $<10 ; 120$ & Toor and Jin (2012) \\
\hline Ca-bentonite & Congo Red & 95.92 & $5 ; 180$ & Lian et al. (2009) \\
\hline Alginate/polyvinyl alcohol-kaolin composite & Methylene Blue & 100 & $>8 ; 360$ & Abd El-Latif et al. (2010) \\
\hline Natural kaolinitic clay & Congo Red & 84 & $5-9 ; 60$ & Nwokem et al. (2012) \\
\hline Burnt kaolinitic clay & Congo Red & 94 & $5-9 ; 60$ & Nwokem et al. (2012) \\
\hline Montmorillonite & Malachite Green & NS & NS; 30 & Tahir et al. (2010) \\
\hline Montmorillonite & Fast Green & NS & NS; 10 & Tahir et al. (2010) \\
\hline Montmorillonitic clay & Basic Blue 16 & NS & 3.6; NS & Gunay et al. (2013) \\
\hline Ghassoul & Methylene Blue & $90-99$ & $4.5-5 ; 10-20$ & Elass et al. (2010) \\
\hline Open burnt clay & Congo Red & 94 & $3 ; 200$ & Mumin et al. (2007) \\
\hline Raw Moroccan clay & Malachite Green & NS & NS; 25 & Bennani-Karim et al. (2011) \\
\hline Moroccan clay & Basic Red 46 & 95 & $9.5 ; 20$ & Bennani-Karim et al. (2009) \\
\hline Raw clay (Fouchana clay) & Reactive Red 120 & NS & $5-5.7 ; 20$ & Errais et al. (2012) \\
\hline Raw clay (smectite) & Reactive Red 120 & NS & $9-9.3 ; 60$ & Errais et al. (2012) \\
\hline Raw clay (kaolinite) & Reactive Red 120 & NS & $5-5.7 ; 20$ & Errais et al. (2012) \\
\hline Raw clay (illite) & Reactive Red 120 & NS & $9-9.3 ; 60$ & Errais et al. (2012) \\
\hline Activated clay & Basic Red & NS & $3 ; 30$ & Hsu et al. (1997) \\
\hline Activated clay & Basic Red 46 & NS & $3 ; 30$ & Hsu et al. (1997) \\
\hline Activated clay & Basic Yellow 28 & NS & $3 ; 30$ & Hsu et al. (1997) \\
\hline
\end{tabular}

NS not stated

\section{$\mathrm{TiO}_{2}$ interlayer-pillared clays}

The use of $\mathrm{TiO}_{2}$ interlayer-pillared clays has been widely studied notably for their high efficiency/catalytic activity, low cost, long-term stability, regeneration and reuse (Herney-Ramírez and Madeira 2010). Ding et al. reported the adsorption of methyl orange (MO) on hydrophobic $\mathrm{TiO}_{2}$-pillared clay prepared from montmorillonite clay (MC) using acetic acid (MCHA) and $\mathrm{HCl}$ solution (MCHCL). The adsorption equilibrium was reached within 20 min at room temperature and the $\mathrm{TiO}_{2}$-pillared $\mathrm{MCHA}$ and MCHCL had better adsorption capability to MO than the raw MC. Higher percentage of the starting concentration of MO was adsorbed on MCHA (26.4\%) and MCHCL $(25.2 \%)$ as compared to raw MC (10.0\%). The adsorption of dyes and other organics from water is not only influenced by the specific surface area, but also affected by the hydrophobicity or the polarity of adsorbents. Since water is preferentially adsorbed on the hydrophilic clay matrix, its surface should be hydrophilic. When the clay was modified with acetic acid and $\mathrm{HCl}$, its surface became more hydrophobic and possessed larger adsorption capacity to organic pollutants (MO). The high cost and the complicated separation process of the titanium catalyst particles from aqueous system hinder the large-scale industrial applications of $\mathrm{TiO}_{2}$-based technology. However, clay has better sedimentation and precipitation properties which can be used in recycling the adsorbent. Recovery studies showed that MCHA (75\% in $60 \mathrm{~min}$ and $83 \%$ in $240 \mathrm{~min}$ ) had better precipitation performance than Degussa $\mathrm{P}_{25} \mathrm{TiO}_{2}(3 \%$ in $60 \mathrm{~min}$ and $8 \%$ in $240 \mathrm{~min}$ ) which is a commonly available commercial $\mathrm{TiO}_{2}$. There was no sedimentation of Degussa P25 $\mathrm{TiO}_{2}$ within the experiment time (240 min); thus, the MCHA has much higher recovery efficiency than Degussa P25 $\mathrm{TiO}_{2}$, suggesting that the former can be more suitable in wastewater treatment (Ding et al. 2008).

Photodegradation and photocatalysis of organic pollutants including dyes using $\mathrm{TiO}_{2}$ interlayer-pillared clays has been subject to numerous studies in the last decades. 
Yang et al. investigated the time-dependent concentration variation of $\mathrm{MO}$ in aqueous solution suspended in $\mathrm{TiO}_{2}$ pillared clays under UV irradiation $(1>290 \mathrm{~nm})$ for $120 \mathrm{~min}$. Excellent photocatalytic activities were observed as the concentration of $\mathrm{MO}$ with the $\mathrm{TiO}_{2}$-pillared clay catalysts decreased drastically upon increasing the UV light irradiation time, whereas no photocatalytic degradation of MO was observed without the photocatalyst within the irradiation time. Larger specific surface area catalysts showed higher activity, thus confirming the importance of nanoporosity in the catalysts. The authors noted that the photocatalytic activity of TK-500 (with less transparent clay support; Kunipia-G) was found to be considerably lower than that of TM-500 (with transparent clay support; Na-mica), even though TK-500 has significantly higher $\mathrm{TiO}_{2}$ content $(56.9 \mathrm{wt} \%)$ and specific surface area (314 $\mathrm{m}^{2} \mathrm{~g}^{-1}$ ) than TM-500 (34.0 wt\% and $\left.242 \mathrm{~m}^{2} \mathrm{~g}^{-1}\right)$. They proposed that such unusual photocatalytic property of the $\mathrm{TiO}_{2}$-pillared clays with different textural parameters was due to the difference in the optical transparency of the host clay layers. These results indicated that the photocatalytic activities of $\mathrm{TiO}_{2}$-pillared clays was significantly affected by the optical transparency of host clay lattice, as well as their specific surface areas (Yang et al. 2015).

The photocatalytic performances of the $\mathrm{TiO}_{2}$-pillared montmorillonite $(\mathrm{Mt})$ on $\mathrm{MB}$ under UV light reported by Chen and co-workers showed that in the absence of the photocatalyst, the photolysis of $\mathrm{MB}$ is only $8 \%$. The degradation efficiency of $\mathrm{TiO}_{2}$ Degusa P-25 (46\%) was much lower than the TiPx-Mt-y samples [x: amount of poly(ethylene oxide) (POP); 1-3 g added and y: calcination temperature between 300 and $900{ }^{\circ} \mathrm{C}$ ]. However, the authors observed that the photocatalytic activity of TiPxMt-500 was higher than that of Ti-Mt-500 (without POP) with maximum removal efficiency of MB for TiP1.5-Mt$500(83 \%)$ within $90 \mathrm{~min}$, indicating that the photocatalytic activities of the $\mathrm{TiO}_{2}$-pillared montmorillonite (Mt) is not a function of the Ti loading of the samples, but a function of the contact between the catalyst and the dye to be degraded. Increase in calcination temperature decreased the photocatalytic activities of TiP2-Mt-y, probably due to the collapse of some pores and thus decreasing the specific surface area and pore volume, as larger specific surface areas and large pore volumes are required for adsorbents/catalysts for removing organic compounds from wastewater. Photocatalytic performance also strongly depended on the crystallinity and grain size of the samples, as observed in TiP2-Mt-400 with higher photocatalytic activity (98\%) than TiP2-Mt-200 (Chen et al. 2012b).

Moroccan palygorskite fibres were used in the photocatalytic degradation of Orange $G(\mathrm{OG})$ pollutant from wastewater. The $\mathrm{TiO}_{2}$-supported palygorskite sample annealed in air at $600{ }^{\circ} \mathrm{C}$ for $1 \mathrm{~h}$ (CTA ${ }^{+}$-Pal-Ti-600-1) showed the highest photocatalytic activity (89\%) towards the degradation of OG compared to nanocomposite samples prepared under different conditions as well as pure $\mathrm{TiO}_{2}$ powders obtained from the xerogel route or commercially available Degussa P25. The best photocatalytic activity between 500 and $600{ }^{\circ} \mathrm{C}$ was observed with average crystallite size of anatase at $8 \mathrm{~nm}$. The increased size of anatase crystallite led to decreased photocatalytic activity above this temperature range. However, increased annealing temperature reduced the activity, although they were still active at $900{ }^{\circ} \mathrm{C}$ ( $25 \%$ of OG removed) probably due to the good thermal stability and structural changes of anatase on increasing temperature and annealing time. The initial amount of OG disappeared in approximately $90 \mathrm{~min}$ with the nanocomposite materials annealed at $500{ }^{\circ} \mathrm{C}$ and there was better efficiency at $600{ }^{\circ} \mathrm{C}$, below which lower efficiencies (50\% of the initial dye amount was degraded in $150 \mathrm{~min}$ ) were observed at higher temperatures thus exhibiting important photocatalytic activity. This was attributed to the formation of anatase nanoparticles as supported by powder X-ray diffraction studies and the crystallization of the less active rutile phase at high temperatures. In comparison with commercial Degussa P25 and $\mathrm{TiO}_{2}$ obtained by the xerogel route, the photocatalytic activity of $\mathrm{TiO}_{2}$-supported palygorskite nanocomposites (CTA ${ }^{+}$-Pal-Ti-600-1 sample) showed twice higher activity with small size and better dispersion of $\mathrm{TiO}_{2}$ nanoparticles immobilized on the palygorskite fibres, which prevented agglomeration and maintained high specific surface area, thus accounting for the good efficiency (Bouna et al. 2011).

Photodegradation of CR using $\mathrm{TiO}_{2}$-pillared Romanian clay under UV irradiation was studied by Dvininov's group. The combination of the adsorptive capacity of the Romanian clay and the ability of $\mathrm{TiO}_{2}$ to efficiently photooxidize $\mathrm{CR}$ in aqueous solution was utilized at room temperature and $\mathrm{pH} 4$ with the maximum dye absorption observed at $\mathrm{pH} 1$ due to dye coagulation, thus using a higher $\mathrm{pH}$ to avoid this process. Although maximum $\mathrm{CR}$ absorption has been reported in the basic environment $(\mathrm{pH}$ 10), high amounts of adsorbents are required to get a $50 \%$ removal. UV irradiation of the $\mathrm{CR}$ solution in the absence of photocatalyst showed that $20 \%$ of the dye was removed by photolysis, while approximately $10 \%$ of the dye was adsorbed by the composite in the dark. However, about $40 \%$ of the dye was removed in $1 \mathrm{~h}$ by photocatalysis, which is relatively low in efficiency. $\mathrm{TiO}_{2}$-pillared Romanian clay samples prepared using the direct method (TiVC) and indirect method (TiVCS1 and TiVCS2) showed increased CR removal efficiency from $25.4 \%$ (TiVC) to $42.7 \%$ (TiVCS1) and $90 \%$ (TiVCS2) using identical experimental conditions after only $10 \mathrm{~min}$, while all the CR in the solution was removed by TiVCS2 after $30 \mathrm{~min}$, showing the highest efficiency for the dye 
oxidation. Thus, the photocatalytic activity of the pillared clays was not a function of Ti loading of the samples, but a function of the contact between catalyst and the dye to be degraded, $\mathrm{TiO}_{2}$ pillar size and photoactive species present in the interlayer space (Dvininov et al. 2009).

\section{Challenges and future prospects}

The literatures reviewed so far revealed that there was need for more detailed studies in dye removal processes and improvements in the preparation and utilization of clay adsorbents. Several issues need more attention in future studies of clay materials as adsorbents for dyes. Amongst these are enhancement of sorption capacity through modification and mechanistic modelling to correctly understand the sorption mechanisms. The interaction between adsorbates and the adsorbents must be investigated in more detail to establish the relationships and roles of functional groups in the dye adsorption process. Critical investigation is needed in studying the adsorptive properties and the molecular structure/surface group of the adsorbents, as this will be helpful in the development of micro/meso porosity. Extensive research must be conducted to bring to limelight the expansive laboratory efforts to design and carry out some pilot-scale studies to check the feasibility of these clay adsorbents at the industrial level.

The difficulty in separating adsorbate-adsorbent mixture after adsorption limits the practical application of clay materials as adsorbents. A lot of researches are in progress to explore new and modified methods that can not only separate clay materials from water effectively, but also improve the dye removal rate. This quest should also be tailored towards getting raw/modified clay materials with short contact time, as this will make it easier to use clay as adsorbents industrially. In addition, the clay minerals are in nanometre scale, so they have large specific surface area that greatly favours adsorption. However, this advantage has not been brought to the limelight because of the difficulties in the dispersion or separation procedures.

The processes of regeneration and reuse of these clay materials are of high interest; thus, extensive research is needed to find better physical methods for regeneration. Regeneration of the adsorbent by desorption is not feasible; therefore, cost-effective and feasible regeneration methods must be developed to make use of these clay materials with real industrial dye effluents economically viable. The regeneration of used clay adsorbents employing the conventional methods for regeneration of spent adsorbent, i.e. thermal treatment and acid and base treatment, in a controlled atmosphere should minimize drastically the oxidation of the adsorbent particles. Mechanistic details of the regeneration and reuse of $\mathrm{TiO}_{2}$ interlayer-pillared clays should be explored to bring the science to an industrial scale level. Since a large number of clay materials are obtained locally, researchers utilizing clay materials for dye removal can work and promote the mantra "think globally, act locally".

\section{Conclusion}

From the various studies so far examined, it is evident that different types of clay have shown high efficiencies for dye removal, with activated/modified clays showing higher adsorption capacities than raw clays. The sorption properties of clays as adsorbent for the removal of diverse type of dyes from water and wastewater have been reviewed based on a substantial number of relevant published articles considering various process parameters. The effect of temperature, initial dye concentration, contact time, adsorbent dosage, $\mathrm{pH}$, and kinetic and thermodynamic parameters influencing the sorption processes has been discussed in detail. The development of highly efficient clay adsorbents (especially the activated/modified forms) is essential for industrial applications. Potential ways of improving the performance of clay adsorbents have also been suggested. Additional research is also needed to gain a better understanding of the mechanism of dye adsorption on activated clays and $\mathrm{TiO}_{2}$ interlayer-pillared clays, especially about surface morphology after modification/activation, as the information available on the possible mechanism of dye sorption by clay materials needs further explanation.

Acknowledgments The corresponding author acknowledges the support obtained from the Third World Academy of Science (TWAS) in the form of a grant: Research Grant number: 11-249 RG/CHE/AF/ AC_1_UNESCO FR: 3240262674.

Open Access This article is distributed under the terms of the Creative Commons Attribution 4.0 International License (http:// creativecommons.org/licenses/by/4.0/), which permits unrestricted use, distribution, and reproduction in any medium, provided you give appropriate credit to the original author(s) and the source, provide a link to the Creative Commons license, and indicate if changes were made.

\section{References}

Abd El-Latif MM, Ibrahim AM, El-Kady MF (2009) Kinetic and thermodynamic approach of organic dye adsorption on biopolymer-kaolin composite. Alex Eng J 48:137-149

Abd El-Latif MM, El-Kady MF, Ibrahim AM, Ossman ME (2010) Alginate/polyvinyl alcohol-kaolin composite for removal of methylene blue from aqueous solution in a batch stirred tank reactor. J Am Sci 6:280-292

Adeyemo AA, Adeoye IO, Bello OS (2012) Metal organic frameworks as adsorbents for dye adsorption: overview, prospects and future challenges. Toxicol Environ Chem 94(10):1846-1863 
Ahmad R, Kumar R (2010) Adsorption studies of hazardous malachite green onto treated ginger waste. J Environ Manag 91:1032-1038

Aksu Z (2005) Application of biosorption for the removal of organic pollutants: a review. Process Biochem 40:997-1026

Akyuz S, Akyuz T, Davies JED (1993a) An FT-IR spectroscopic investigation of the adsorption of benzidine by sepiolite from Eskisehir (Turkey). J Mol Struct 293:279-282

Akyuz S, Akyuz T, Davies JED (1993b) A vibrational spectroscopic study of the adsorption of 4,4'-bipyridyl by sepiolite and smectite group clay minerals from Anatolia (Turkey). J Inclusion Phenom Mol Recognit Chem 15:105-119

Al-Asheh S, Abu-Aitah BF (2003) The removal of methylene blue dye using activated and non-activated bentonite solutions. Adsorpt Sci Technol 21:451-462

Albarins TA, Hela TM (1993) Removal of dyes from aqueous solutions by adsorption on mixture of fly ash soil in batch and column techniques. Department of Chemistry, University of Loannins, Loanina

Al-Degs Y, Khraisheh MA, Allen SJ, Ahmed MN (2000) Evaluation of activated carbon adsorbents for the removal of textile reactive dyes from wastewater. J Int Chem Eng Conf 1:159-167

Arivoli S, Thenkuzhali M (2008) Kinetic, mechanistic, thermodynamic and equilibrium studies on the adsorption of Rhodamine $\mathrm{B}$ by acid activated low cost carbon. Electron J Chem 5:187-200

Aznar AJ, Casal B, Ruiz-Hitzky E, Lopez-Arbeloa I, Lopez-Arbeloa F, Santaren J, Alvarez A (1992) Adsorption of methylene blue on sepiolite gels. Spectroscopic and rheological studies. Clay Miner 27:101-108

Baek MH, Ijagbemi CO, Oh SJ, Kim DS (2010) Removal of Malachite Green from aqueous solution using degreased coffee bean. J Hazard Mater 176:820-828

Bailey SW (1980) Summary of recommendations of AIPEA nomenclature committee on clay minerals. Am Mineral 65:1-7

Banat F, Al-Ashe S, Al-Makhadmeh L (2003) Evaluation of the use of raw and activated date pits as potential adsorbents for dye containing waters. Process Biochem 39:193-202

Bellir K, Bencheikh-Lehocine M, Meniai A-H (2010) Removal of methylene blue from aqueous solutions using an acid activated Algerian bentonite: equilibrium and kinetic studies. Int Renew Energy Congr 2010:360-367

Bello OS (2013) Adsorptive removal of Malachite Green with activated carbon prepared from oil palm fruit fibre by $\mathrm{KOH}$ activation and $\mathrm{CO}_{2}$ gasification. S Afr J Chem 66:32-41

Bello OS, Ahmad MA (2011a) Adsorptive removal of a synthetic textile dye using coca pod husks. Toxicol Environ Chem 93:1298-1308

Bello OS, Ahmad MA (2011b) Adsorption of dyes from aqueous solution using chemical activated mango peels. In: 2nd international conference on environmental science and technology (ICEST), vol 2, pp 108-113

Bello OS, Ahmad MA (2011c) Response surface modelling and optimization of remazol brilliant blue reactive dye removal using periwinkle shell based activated carbon. Sep Sci Technol 46:2367-2379

Bello OS, Ahmad MA (2011d) Removal of remazol brilliant violet5R dye using periwinkle shell. Chem Ecol 27:481-492

Bello OS, Ahmad MA (2012a) Preparation and characterization of activated carbon derived from rubber seed coat. Bulg J Sci Educ 21:389-395

Bello OS, Ahmad MA (2012b) Coconut (Cocos nucifera) shell based activated carbon for the removal of malachite green dye from aqueous solutions. Sep Sci Technol 47:903-912

Bello OS, Semire B (2012) Equilibrium, kinetic and quantum chemical studies on the adsorption of Congo red using Imperata cylindrica leaf powder activated carbon. Toxicol Environ Chem 94:1114-1124

Bello OS, Adeogun IA, Ajaelu JC (2008) Adsorption of methylene blue onto activated carbon derived from periwinkle shells: kinetics and equilibrium studies. Chem Ecol 24:285-295

Bello OS, Ahmad MA, Ahmad N (2012a) Adsorptive features of banana (Musa paradisiaca) stalk-based activated carbon for malachite green dye removal. Chem Ecol 28:153-167

Bello OS, Fatona TA, Falaye FS, Osuolale OM, Njoku VO (2012b) Adsorption of eosin dye from aqueous solution using groundnut hull-based activated carbon: kinetic, equilibrium, and thermodynamic studies. Environ Eng Sci 29:186-194

Bello OS, Olusegun OA, Njoku VO (2013a) Fly ash: an alternative to powdered activated carbon for the removal of eosin dye from aqueous solutions. Bull Chem Soc Ethiop 27(2):191-204

Bello OS, Auta M, Ayodele OB (2013b) Ackee apple (Blighia sapida) seeds: a novel adsorbent for the removal of Congo Red dye from aqueous solutions. Chem Ecol 29:58-71

Bellotto M, Gualtieri A, Artioli G, Clark SM (1995) Kinetic study of the kaolinite-mullite reaction sequence. Part I: kaolinite dehydroxylation. Phys Chem Miner 22:207-214

Benefield DL, Judkins JF, Weand BL (1982) Process chemistry for water and wastewater treatment. Prentice-Hall Inc., NJ, USA

Bennani-Karim A, Mounir B, Hachkar M, Bakasse M, Yaacoubi A (2009) Removal of Basic Red 46 dye from aqueous solution by adsorption onto Moroccan clay. J Hazard Mater 168:304-309

Bennani-Karim A, Mounir B, Hachkar M, Bakasse M, Yaacoubi A (2011) Adsorption of malachite green dye onto raw Moroccan clay in batch and dynamic system. Can J Environ Constr Civ Eng 2:5-13

Bernal MP, Lopez-Real JM (1993) Natural zeolites and sepiolite as ammonium and ammonia adsorbent materials. Bioresour Technol 43:27-33

Bhatnagar A, Vilar VJP, Botelho CMS, Boaventura RAR (2011) A review of the use of red mud as adsorbent for the removal of toxic pollutants from water and wastewater. Environ Technol $32: 231-249$

Bouna L, Rhouta B, Amjoud M, Maury F, Lafont M-C, Jada A, Senocq F, Daoudi L (2011) Synthesis, characterization and photocatalytic activity of $\mathrm{TiO}_{2}$ supported natural palygorskite microfibers. Appl Clay Sci 52:301-311

Breen C (1991) Thermogravimetric study of the desorption of cyclohexylamine and pyridine from and acid-treated Wyoming bentonite. Clay Miner 26:473-486

Breen C (1994) Thermogravimetric, infra-red and mass spectroscopic analysis of the desorption of tetrahydropyran, tetrahydrofuran and 1,4-dioxan from montmorillonite. Clay Miner 29:115-121

Cabal B, Budinova T, Ania CO, Tsyntsarski B, Parra JB, Petrova B (2009) Adsorption of naphthalene from aqueous solution on activated carbons obtained from bean pods. J Hazard Mater 161:1150-1156

Cailleres S, Henin S (1961) Palygorskite. In: Brown G (ed) The X-ray identification and crystal structures of clay minerals, chap 9. Mineralogical Society, London

Chen C-C, Hayes KF (1999) X-ray absorption spectroscopy investigation of aqueous $\mathrm{Co}$ (II) and $\mathrm{Sr}$ (II) sorption at clay-water interfaces. Geochim Cosmochim Acta 63:3205-3215

Chen B, Hui CW, McKay G (2001) Pore surface diffusion modelling for dyes from effluent on pith. Langmuir 17:740-748

Chen Y-M, Tsao T-M, Wang M-K (2011) Removal of crystal violet and methylene blue from aqueous solution using soil nano-clays. In: International conference on environment science and engineering, IPCBEE, vol 8. IACSIT Press, Singapore, pp 252-254

Chen C, Zhang M, Guan Q, Li W (2012a) Kinetic and thermodynamic studies on the adsorption of xylenol orange onto MIL-101(Cr). Chem Eng J 183:60-67 
Chen D, Zhu Q, Zhou F, Deng F, Li F (2012b) Synthesis and photocatalytic performances of the $\mathrm{TiO}_{2}$-pillared montmorillonite. J Hazard Mater 235-236:186-193

Daehn R, Scheidegger AM, Manceau A, Schlegel ML, Baeyens B, Bradbury MH, Chateigner D (2003) Structural evidence for the sorption of $\mathrm{Ni}(\mathrm{II})$ atoms on the edges of montmorillonite clay minerals: a polarized X-ray absorption fine structure study. Geochim Cosmochim Acta 67:1-15

Dave R, Madamwar D (2006) Esterification in organic solvents by lipase immobilized in polymer of PVA-alginate-boric acid. Process Biochem 41:951-955

Deer WA, Howie RA, Zussman J (1992) An introduction to the rockforming minerals (2nd Edition). Longman, Harlow

Demir H, Top A, Balkose D, Lku SU (2008) Dye adsorption behaviour of Luffa cylindrica fibres. J Hazard Mater 153:389-394

Din ATM, Hameed BH, Ahmad AL (2009) Batch adsorption of phenol onto physiochemical-activated coconut shell. J Hazard Mater 161:1522-1529

Ding X, An T, Li G, Zhang S, Chen J, Yuan J, Zhao H, Chen H, Sheng G, Fu J (2008) Preparation and characterization of hydrophobic $\mathrm{TiO}_{2}$ pillared clay: the effect of acid hydrolysis catalyst and doped Pt amount on photocatalytic activity. J Colloid Interface Sci 320:501-507

Dvininov E, Popovici E, Pode R, Cocheci L, Barvinschi P, Nica V (2009) Synthesis and characterization of $\mathrm{TiO}_{2}$-pillared Romanian clay and their application for azoic dyes photodegradation. J Hazard Mater 167:1050-1056

Ehssan DJ, Shaymaa HK, Hussein AN (2011) A thermodynamic study of adsorption of some dyes on Iraqi bentonite modified clay. Eur J Sci Res 60:63-70

Elass K, Laachach A, Alaoui A, Azzi M (2010) Removal of methylene blue from aqueous solution using ghassoul, a low-cost adsorbent. Appl Ecol Environ Res 8:153-163

Errais E (2011) Thesis, Strasbourg University, p 210

Errais E, Duplaya J, Elhabiri M, Khodjac M, Ocampod R, Baltenweck-Guyote R, Darragi F (2012) Anionic RR120 dye adsorption onto raw clay: surface properties and adsorption mechanism. Colloids Surf A 403:69-78

Espantaleón AG, Nieto JA, Fernández M, Marsal A (2003) Use of activated clays in the removal of dyes and surfactants from tannery waste waters. Appl Clay Sci 24:105-110

Fan QH, Tan XL, Li JX, Wang XK, Wu WS, Montavon G (2009) sorption of $\mathrm{Eu}(\mathrm{III})$ on attapulgite studied by batch, XPS, and EXAFS techniques. Environ Sci Technol 43:5776-5782

Foo KY, Hameed BH (2009a) Value-added utilization of oil palm ash: a superior recycling of the industrial agricultural waste. J Hazard Mater 172:523-531

Foo KY, Hameed BH (2009b) Utilization of rice husk ash as novel adsorbent: a judicious recycling of the colloidal agricultural waste. Adv Colloid Interface Sci 152:39-47

Food and Drug Administration (2011) Database of select committee on GRAS substances (SCOGS). Reviews Bentonite. FDA Database. Retrieved 15 Aug 2011

Gabriel H, Hong J (2008) Decolouration of reactive blue dye KN-R. Res J Appl Sci 3(3):216-224

Gonzalez-Pradas E, Villafranca-Sanchez M, Valverde-García A, Villafranca-Sanchez E (1991) Adsorption of beta-carotene from acetone solution on natural and chemically modified bentonite. Mater Chem Phys 27:307-319

Gonzalez-Pradas E, Villafranca-Sanchez M, Gallego-Campo A (1992) Effects of experimental variables on phosphate adsorption on bentonite. J Chem Technol Biotechnol 54:291-295

Gonzalez-Pradas E, Villafranca-Sanchez M, Socias-Viciana M, Castillo-Sanchez J, Fernandez-Perez M (1993) Removal of 3-(3,4-dichlorophenyl)-1,1-dimethylurea from aqueous solution by natural and activated bentonite. J Chem Technol Biotechnol 56:67-71

Gonzalez-Pradas E, Villafranca-Sanchez M, Socias-Viciana M, Gallego-Campo A (1994) Adsorption of chlorophyll a from acetone solution on natural and activated bentonite. J Chem Technol Biotechnol 61:175-178

Grim RE (1962) Applied clay mineralogy. McGraw-Hill, New York Guggenheim S, Martin RT (1995) Definition of clay and clay mineral: joint report of the AIPEA nomenclature and CMS nomenclature committees. Clay Clay Miner 43:255-256

Gunay A, Ersoy B, Dikmen S, Evcin A (2013) Investigation of equilibrium, kinetic, thermodynamic and mechanism of Basic Blue 16 adsorption by montmorillonitic clay. Adsorption. 19:757-768

Gupta VK, Suhas IA, Saini VK (2004) Removal of rhodamine B, fast green, and methylene blue from wastewater using red mud, an aluminium industry waste. Ind Eng Chem Res 43:1740-1747

Gurses A, Dogar C, Yalcin M, Acikyildiz M, Bayrak R, Karaca S (2006) The adsorption kinetics of the cationic dye, methylene blue, onto clay. J Hazard Mater B131:217-228

Hameed BH (2009a) Spent tea leaves: a new non-conventional and low-cost adsorbent for removal of basic dye from aqueous solutions. J Hazard Mater 161:753-759

Hameed BH (2009b) Evaluation of papaya seeds as a novel nonconventional low cost adsorbent for removal of methylene blue. J Hazard Mater 162:939-944

Han Y, Sheng S, Yang F, Xie Y, Zhaoa M, Li J-R (2015) Sizeexclusive and coordination-induced selective dye adsorption in a nanotubular metal-organic framework. J Mater Chem A 3:12804-12809

Hasan MB (2008) Adsorption of reactive azo dyes on chitosan/oil palm ash composite adsorbent: batch and continuous studies. MSc Thesis, Universiti Sains Malaysia

Herney-Ramírez J, Madeira LM (2010) Use of pillared clay-based catalysts for wastewater treatment, chap 6. In: Gil A, Korili SA, Trujillano R, Vicente MA (eds) Pillared clays and related catalysts. Springer, New York

Hsu Y-C, Chiang CC, Yu MF (1997) Adsorption behaviour of basic dyes on activated clay. Sep Sci Technol 32:2513-2534

$\mathrm{Hu}$ QH, Qiao SZ, Wilson FH (2005) Adsorption study for removal of basic dyes using bentonites. Ind Eng Chem Res 102:885-889

Jaafar SNBS (2006) Adsorption study—dye removal using clay. A B. Chem. Eng. Thesis, Faculty of Chemical Engineering and Natural Resources, University College of Engineering \& Technology

Jhimli P, Naik DB, Sabharwal S (2010) High energy induced decolouration and mineralization of Reactive Red 120 dye in aqueous solution: a steady state and pulse radiolysis study. Radiat Phys Chem 79:770-776

Joan RS, Wu FC, Tseng RL (1997) The ability of activated clay for the adsorption of dyes from aqueous solutions. Environ Technol 18:525-531

Joo JB, Park B, Yi J (2009) Preparation of polyelectrolyte-functionalized mesoporous silicas for the selective adsorption of anionic dye in an aqueous solution. J Hazard Mater 168:102-107

Kannan N, Sundaram MM (2001) Kinetics and mechanism of removal of methylene blue by adsorption on various carbons- a comparative study. Dyes Pigm 51:25-40

Kargi F, Ozmihci S (2004) Biosorption performance of powdered activated sludge for removal of different dyestuffs. Enzym Microb Technol 35:267-271

Kumar KV (2006) Comments on adsorption of acid dye onto organobentonite. J Hazard Mater 137:638-639

Laera G, Jin B, Zhu H, Lopez A (2011) Photocatalytic activity of $\mathrm{TiO}_{2}$ nanofibers in simulated and real municipal effluents. Catal Today 161:147-152 
Lagaly G (1995) Surface and interlayer reactions: bentonites as adsorbents. In: Churchman GJ, Fitzpatrick RW, Eggleton RA (eds) Clays controlling the environment. Proceedings of the 10th international clay conference, Adelaide, Australia. CSIRO Publishing, Melbourne, pp 137-144

Lagaly G, Ziesmer S (2003) Colloid chemistry of clay materials: the coagulation of montmorillonite dispersions. J Colloid Interface Sci 100-102:105-128

Lian L, Guo L, Guo C (2009) Adsorption of Congo red from aqueous solutions onto Ca-bentonite. J Hazard Mater 161:126-131

Liu P, Zhang L (2007) Adsorption of dyes from aqueous solutions or suspensions with clay nano-adsorbents. Sep Purif Technol 58:32-39

Low KS, Lee CK (1997) Quaternized Rice husk as sorbent for Reactive dyes. Bioresour Technol 61:121-125

Malik PK (2004) Dye removal from wastewater using activated carbon developed from sawdust: adsorption equilibrium and kinetics. J Hazard Mater 113:81-88

Markovska L, Meshko V, Noveski V, Marinovski M (2001) Solid diffusion control of the adsorption of basic dyes onto granular activated carbon and natural zeolite in fixed bed columns. J Serb Chem Soc 66:463-475

Menkiti MC, Onukwuli OD (2011) Studies on dye removal from aqueous media using activated coal and clay: an adsorption approach. N Y Sci J 4:91-95

Mietta F, Chassagne C, Winterwerp JJ (2009) Shear-induced flocculation of a suspension of kaolinite as function of $\mathrm{pH}$ and salt concentration. J Colloid Interface Sci 336:134-141

Miller A (2010) Homogenized behaviour from increasingly heterogeneous systems: uranium transport experiments at the intermediate scale. Doctoral dissertation, Colorado School of Mines

Miller AW, Wang Y (2012) Radionuclide interaction with clays in dilute and heavily compacted systems: a Critical Review. Environ Sci Technol 46:1981-1994

Mitchell JK (1993) Fundamentals of soil behaviour, 2nd edn. Wiley, New York, pp 405-445

Mittal A, Krishnan L, Gupta VK (2005) Removal and recovery of malachite green from wastewater using an agricultural waste material, de-oiled soya. Sep Purif Technol 43:125-133

Moore DM, Reynolds RC (1997) X-ray diffraction and the identification and analysis of clay minerals. Oxford University Press, New York

Mumin MA, Khan MMR, Akhter KF, Uddin MJ (2007) Potentiality of open burnt clay as an adsorbent for the removal of Congo red from aqueous solution. Int J Environ Sci Technol 4:525-532

Murray HH (2000) Traditional and new applications for kaolin, smectite, and palygorskite: a general overview. Appl Clay Sci $17: 207-221$

Murray H (2002) Industrial clays case study. Int Inst Environ Dev (IIED) 64:1-9

Nakagawa K, Namba A, Mukai SR, Tamon H, Ariyadejwanich P, Tanthapanichakoon W (2004) Adsorption of phenol and reactive dye from aqueous solution on activated carbons derived from solid wastes. Water Res 38:1791-1798

Namasivayam C, Arasi DJSE (1997) Removal of Congo red from wastewater by adsorption onto waste red mud. Chemosphere 34:401-417

Namasivayam C, Yamuna RT, Arasi DJSE (2001) Removal of acid violet from wastewater by adsorption on waste red mud. Environ Geol 41:269-273

Namasivayam C, Yamuna RT, Arasi DJSE (2002) Removal of procion orange from wastewater by adsorption on waste red mud. Sep Sci Technol 37:2421-2431

Nwokem NC, Nwokem CO, Ayuba AA, Usman YO, Odjobo BO, Ocholi OJ, Batari ML, Osunlaja AA (2012) Evaluation of adsorptive capacity of natural and burnt kaolinitic clay for removal of Congo red dye. Arch Appl Sci Res 4:939-946

Odom IE (1984) Smectite clay minerals: properties and uses. Philos Trans R Soc A 311:391

Ozcan CA, Omerolu Y, Erdoan AS, Ozacan A (2007) Modification of bentonite with a cationic surfactant: an adsorption study of textile dye Reactive Blue-19. J Hazard Mater 140:173-179

Parekh NR, Poskitt JM, Dodd BA, Potter ED, Sanchez A (2008) Soil microorganisms determine the sorption of radionuclides within organic soil systems. J Environ Radioact 99(5):841-852

Pohl WL (2011) Economic geology: principles and practice: metals, minerals, coal and hydrocarbon-introduction to formation and sustainable exploitation of mineral deposits. Wiley-Blackwell, Chichester

Purkait MK, Maiti A, DasGupta S, De S (2007) Removal of Congo red using activated carbon and its regeneration. J Hazard Mater 145:287-295

Rajeshwarisivaraj, Sivakumar S, Senthilkumar P, Subburam V (2001) Carbon from cassava peel, an agricultural waste, as an adsorbent in the removal of dyes and metal ions from aqueous solution. Bioresour Technol 80:233-235

Ramakrishna KR, Viraraghavan T (1997) Dye removal using low cost adsorbents. Water Sci Technol 36:189-196

Rao SM, Thyagaraj T (2007) Role of direction of salt migration on the swelling behaviour of compacted clays. Appl Clay Sci 38(1-2):113-129

Robertson RHS (1986) Fuller's Earth: A History of calcium montmorillonite. Volturna Press, U.K

Robinson T, McMullan G, Marchant R, Nigam P (2001) Remediation of dyes in textile effluent: a critical review on current treatment technologies with a proposed alternative. Bioresour Technol $77: 247-253$

Robinson T, Chandran B, Nigam P (2002) Removal of dyes from a synthetic textile dye effluent by biosorption on apple pomace and wheat straw. Water Res 36:2824-2830

Sheng GD, Yang ST, Sheng J, Hu J, Tan X, Wang XK (2011) Macroscopic and microscopic investigation of $\mathrm{Ni}(\mathrm{II})$ sequestration on diatomite by batch, XPS and EXAFS techniques. Environ Sci Technol 45:7718-7726

Sheng G, Dong H, Li Y (2012) Characterization of diatomite and its application for the retention of radiocobalt: role of environmental parameters. J Environ Radioact 113:108-115

Sheng G, Shen R, Dong H, Li Y (2013) Colloidal diatomite, radionickel, and humic substance interaction: a combined batch, XPS, and EXAFS investigation. Environ Sci Pollut Res 20:3708-3717

Singer A (1989) Palygorskite and sepiolite group minerals. In: Weed SB (ed) Minerals in soil environments, 2nd edn. Soil Science Society of America, Madison

Smith JA, Jaffe PR (1994) Adsorptive selectivity of organic-cation modified bentonite for non-ionic contaminants. Water Air Soil Pollut 72:205-211

Spark KM, Wells JD, Johnson BB (1995) Characterizing trace metal adsorption on kaolinite. Eur J Soil Sci 46:633-640

Stockmeyer MR (1991) Adsorption of organic compounds on organophilic bentonites. Appl Clay Sci 6:39-57

Stockmeyer M, Kruse K (1991) Adsorption of Zn and Ni ions and phenol and diethylketones by bentonites of different organophilicities. Clay Miner 26:431-434

Suraj G, Iyer CSP, Rugmini S, Lalithambika M (1998) Adsorption of cadmium and copper by modified kaolinites. Appl Clay Sci 13:293-306

Tahir SS, Naseem R (2006) Removal of a cationic dye from aqueous solutions by adsorption onto bentonite clay. Chemosphere 63:1842-1848 
Tahir H, Hammed U, Sultan M, Jahanze Q (2010) Batch adsorption technique for the removal of malachite green and fast green dyes by using montmorillonite clay as adsorbent. Afr J Biotechnol 9:8206-8214

Tanthapanichakoon W, Ariyadejwanich P, Japthong P, Nakarawa K, Mukai SR, Tamon H (2005) Adsorption-desorption characteristics of phenol and reactive dyes from aqueous solution on mesoporous activated carbon prepared from waste tires. Water Res 39:1347-1353

Tombàcz E, Szekeres M (2006) Surface charge heterogeneity of kaolinite in aqueous suspension in comparison with montmorillonite. Appl Clay Sci 34:105-126

Toor M, Jin B (2012) Adsorption characteristics, isotherm, kinetics, and diffusion of modified natural bentonite for removing diazo dye. Chem Eng J 187:79-88

Tor A, Cengeloglu Y (2006) Removal of Congo red from aqueous solution by adsorption onto acid activated red mud. J Hazard Mater 138:409-415

Tulin BL, Gamze G (2009) Removal of basic dyes from aqueous solutions using natural clay. Desalination 249:1377-1379

Tunega D, Haberhauer G, Gerzabek MH, Lischka H (2002) Theoretical study of adsorption sites on the (001) surfaces of 1:1 clay minerals. Langmuir 18:139-147

Urses AG, Dogar C, Yalcyin M, Bayrak R, Karaca S (2006) The adsorption kinetics of the cationic dye, methylene blue, onto clay. J Hazard Mater B131:217-228

Valix M, Cheung WH, McKay G (2004) Preparation of activated carbon using low temperature carbonization and physical activation of high Ash raw bagasse for acid dye adsorption. Chemosphere 56:493-501

Velde B (1995) Origin and mineralogy of clays, vol 12. Springer, Berlin

Wang S, Boyjoo Y, Choueib A, Zhu ZH (2005) Removal of dyes from aqueous solution using fly ash and red mud. Water Res 39:129-138

Wu FC, Hsu YC, Tseng RL (1994) Adsorption of dyes by activated clay. J Chin Inst Environ Eng 4:207-216

Yahaya NEM, Pakir MF, Latiff M, Abustan I, Bello OS, Ahmad MA (2010a) Process optimisation for $\mathrm{Zn}$ (II) removal by activated carbon prepared from rice husk using chemical activation. Int $\mathbf{J}$ Eng Technol 10:132-136

Yahaya NEM, Pakir MF, Latiff M, Abustan I, Bello OS, Ahmad MA (2010b) Effect of preparation conditions of activated carbon prepared from rice husk by $\mathrm{CO}_{2}$ activation for removal of $\mathrm{Cu}(\mathrm{II})$ from aqueous solution. Int J Eng Technol 10:47-51
Yahaya NEM, Pakir MF, Latiff M, Abustan I, Bello OS, Ahmad MA (2011a) Adsorptive removal of $\mathrm{Cu}$ (II) using activated carbon prepared from rice husk by $\mathrm{ZnCl}_{2}$ activation and subsequent gasification with $\mathrm{CO}_{2}$. Int J Eng Technol 11:207-211

Yahaya NEM, Pakir MF, Latiff M, Abustan I, Bello OS, Ahmad MA (2011b) Fixed bed column study for $\mathrm{Cu}(\mathrm{II})$ removal from aqueous solutions using rice husk based activated carbon. Int $\mathrm{J}$ Eng Technol 11:248-252

Yan A-X, Yao S, Li Y-G, Zhang Z-M, Lu Y, Chen W-L, Wang E-N (2014) Incorporating polyoxometalates into a porous MOF greatly improves its selective adsorption of cationic dyes. Chemistry 20:6927-6933

Yang S, Sheng G, Tan X, Hu J, Du J, Montavon G, Wang X (2011a) Determination of $\mathrm{Ni}(\mathrm{II})$ uptake mechanisms on mordenite surfaces: a combined macroscopic and microscopic approach. Geochim Cosmochim Acta 75:6520-6534

Yang S, Hu J, Chen C, Shao D, Wang X (2011b) Mutual effect of $\mathrm{Pb}$ (II) and humic acid adsorption onto multiwalled carbon nanotubes/poly(acrylamide) composites from aqueous solution. Environ Sci Technol 45:3621-3627

Yang J-H, Piao H, Vinu A, Elzatahry AA, Paek S-M, Choy J-H (2015) $\mathrm{TiO}_{2}$-pillared clays with well-ordered porous structure and excellent photocatalytic activity. RSC Adv 5:8210-8215

Yariv S (2002) In: Cross H (ed) Organo-clay complexes and interactions, vol 39. Marcel Dekker Inc., New York, pp 463-566

Yue Y, Binder AJ, Song R, Cui Y, Chen J, Hensleyd DK, Dai S (2014) Encapsulation of large dye molecules in hierarchically superstructured metal-organic frameworks. Dalton Trans 43:17893-17898

Zakaria RM, Hassan I, El-Abd MZ, El-Tawil YA (2009) Lactic acid removal from wastewater by using different types of activated clay. In: Thirteenth international water technology conference (IWTC), Hurghada, vol 13, pp 403-416

Zawani Z, Luqman CA, Choong TSY (2009) Equilibrium, kinetics and thermodynamic studies: adsorption of remazol black 5 on the palm kernel shell activated carbon (PKS-AC). Eur J Sci Res 37:63-71

Zbik MS, Smart RSC, Morri GE (2008) Kaolinite flocculation structure. J Colloid Interface Sci 328:73-80

Zhao G, Jiang L, He Y, Li J, Dong H, Wang X, Hu W (2011) Sulfonated graphene for persistent aromatic pollutant management. Adv Mater 23:3959-3963

Zhou Z, Gunter WD (1992) The nature of the surface charge of kaolinite. Clay Clay Miner 40:365-368 